ص ص ص[9r-

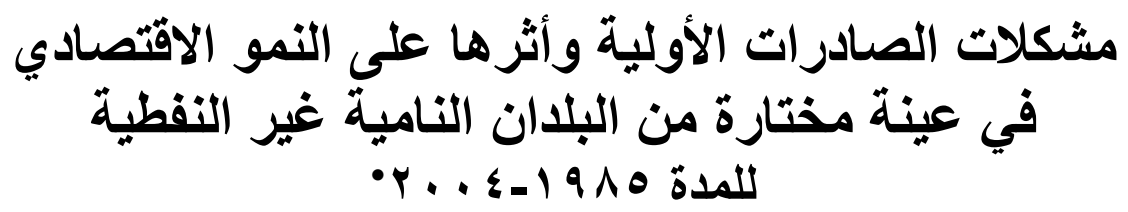

صبحي بكر عثمان

الدكتور طه يونس حادي

ماجستير اقتصاد

Taha-ta98@yahoo.com

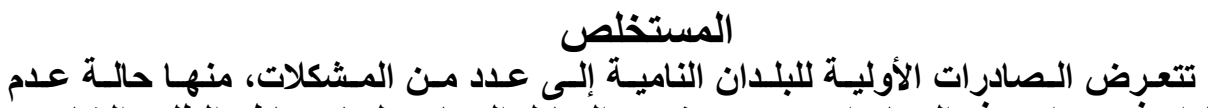

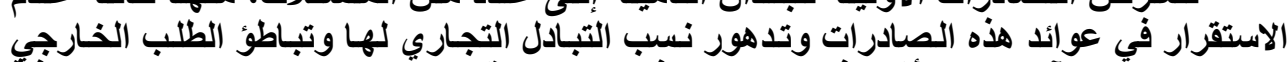

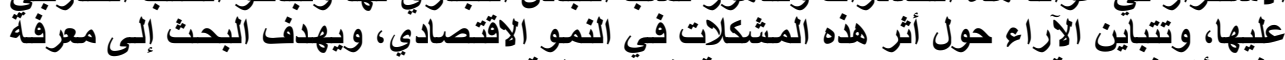

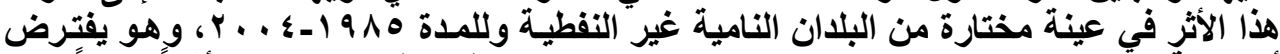

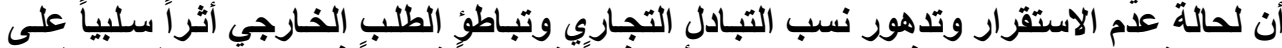

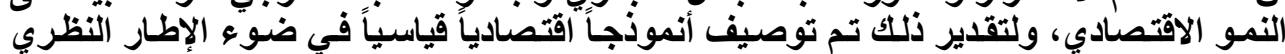

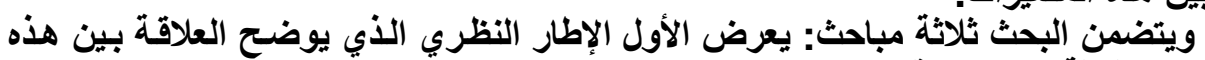
يربط بين هذه المتنغيرات

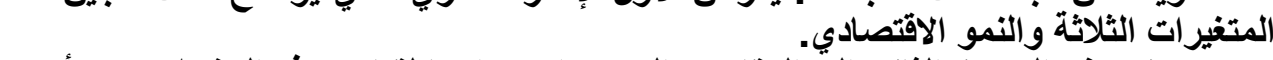

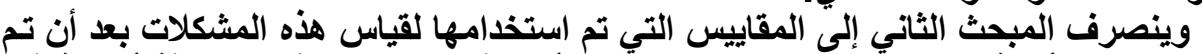

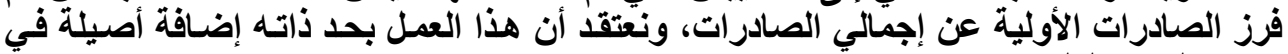

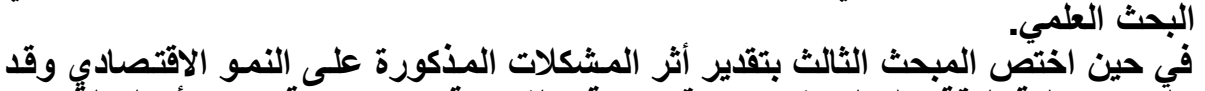

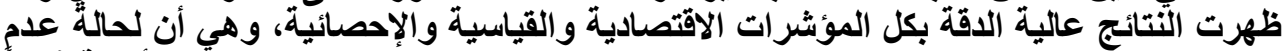

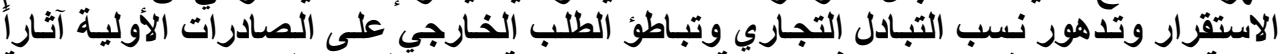

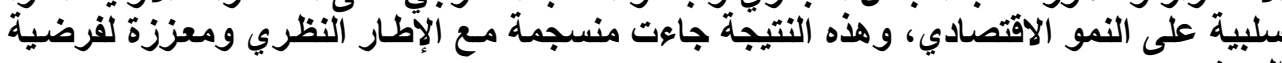

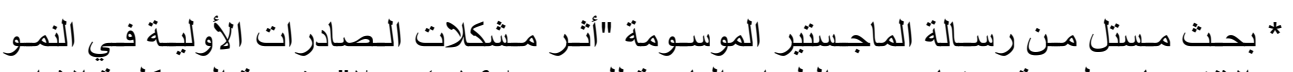

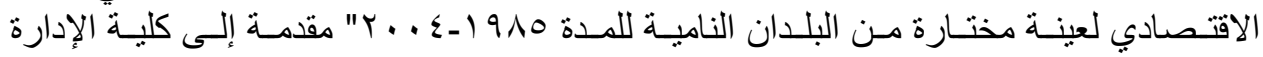
و الاقتصاد.

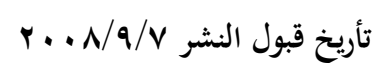$$
\text { تأريخ استلام البحث \&/م/ه . . r }
$$ 


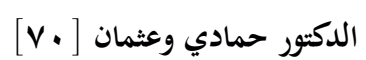

\title{
The Problems of the Primary Exports and its Impact on Economic Growth in Selected Sample of Non-Petroleum Developing Countries in Period from 1985 to 2004
}

Taha Y. Hummady (PhD)

Assistant Professor

Department of Economics

University of Mosul

\author{
Subhi B. Othman
}

M.Sc. in Economics

\begin{abstract}
The primary exports in general may expose to several problems in developing countries. One of these problems is the instability state in exports earnings, deteriorating the rates of commercial exchange, and slowdown external demand. Many views verified the effect of these problems in the economic growth. The current paper aims to study this effect on a sample of non-petroleum developing countries from 1985 - 2004. The study also hypothesized that the instability and deterioration of commercial exchange and slowdown external demand have negative impact on the economic growth. A metrical economic model has been proposed to estimate the variables. The paper consisted of three aspects: the first was theoretical to show the relation among these variables and economic growth. The second was to refer to the measurements used to measure these problems. The third one estimated the effect of problems of economic growth. The conclusions recorded very accurate results in all economic, metrical and statistical indicators - in that- the instability and deteriorating the economic growth, deteriorating the rates of commercial exchange, and slowdown external demand have negative effects on the economic growth. This result comes with the theoretical aspect and promoting the hypothesis.
\end{abstract}

المقدمـة

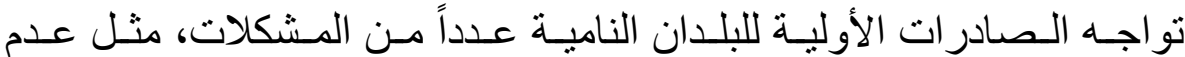

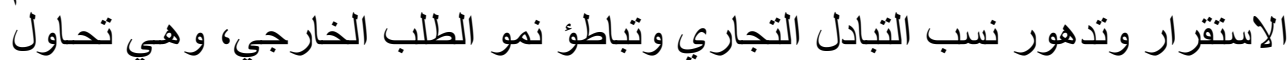

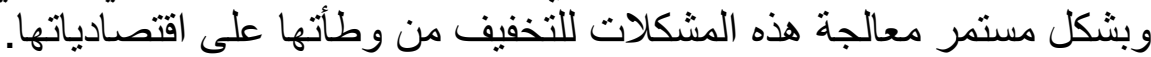

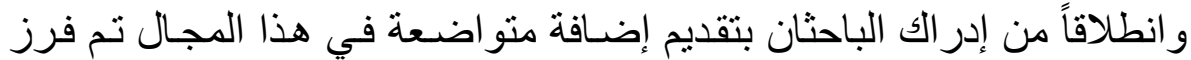

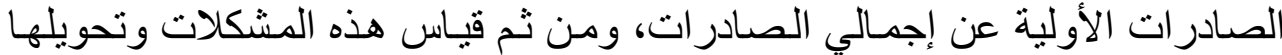

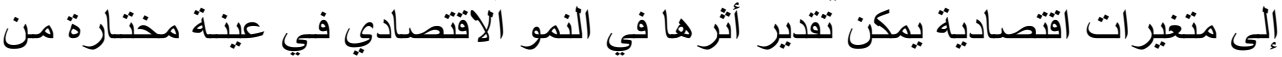

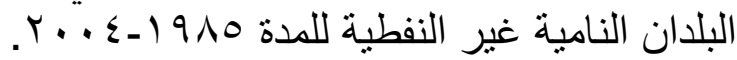

مشكلة البحث

تتعرض الصادر ات الأولية للبلدان النامية إلى عدد من المشكلات، تتمثل بعدم

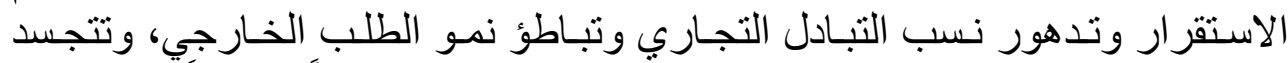

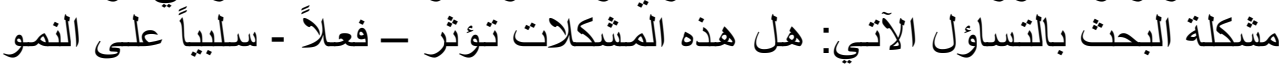

الاقتصادي؟ 


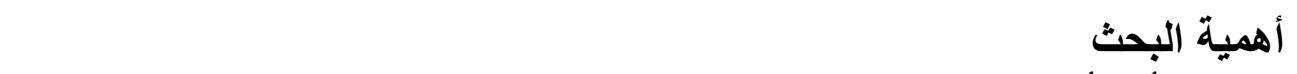

تتأتى أهمية البحث من الاهتمام المتز ايد لادى متخذي القرار في البلدان الناميـة

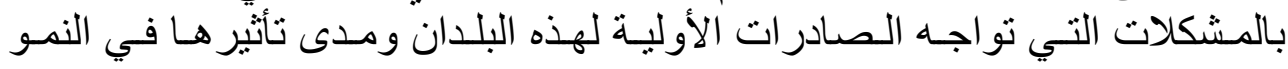

الاقتصادي.

هدف البحث يهدف البحث إلى تقدير وتحليل أثر مشكلات الصادر ات الأولية، وهي عدم

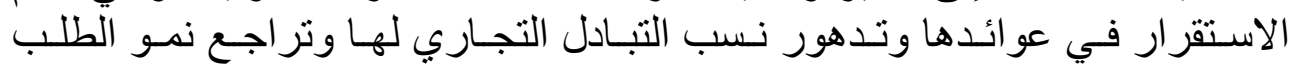

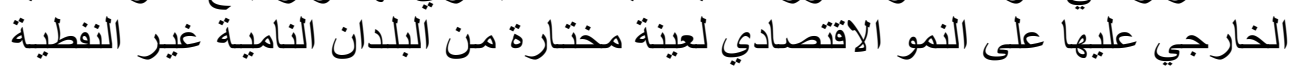

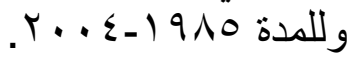

فرضية البحث ل يسـتند البحـث إلـى فرضـية مفادهـا أن هنـالك آثـار أ سـلبية تتركهـا مسشكلات

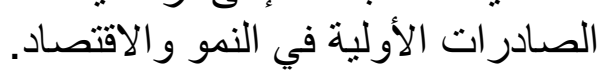

\section{الأسلوب المستخدم في البحث}

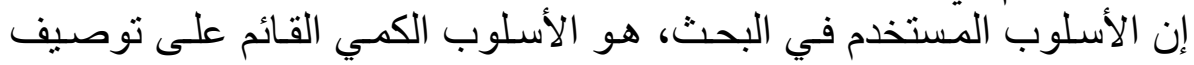

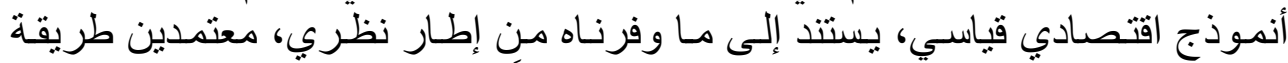

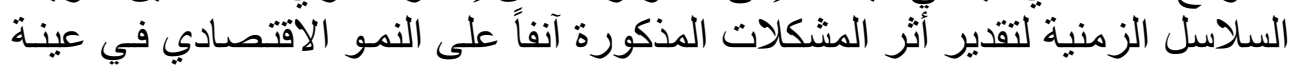

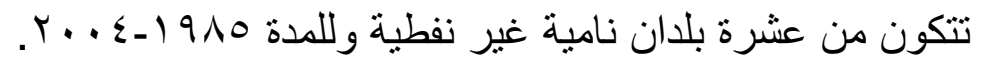

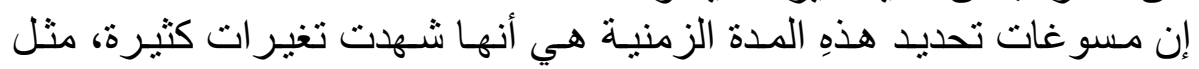

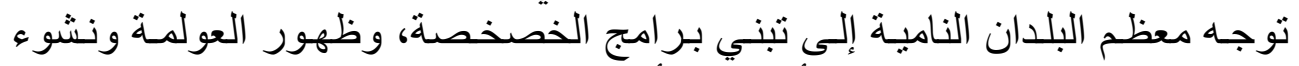

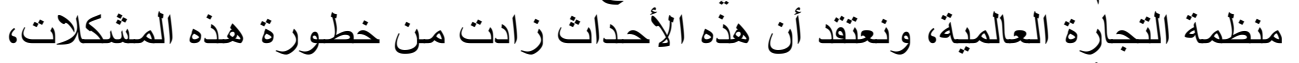

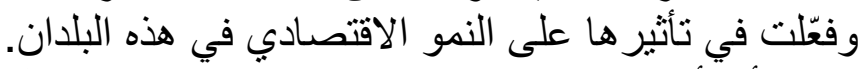

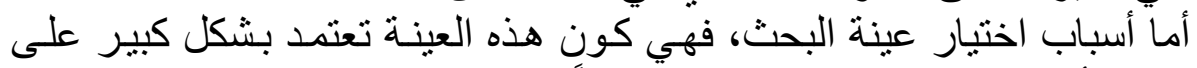

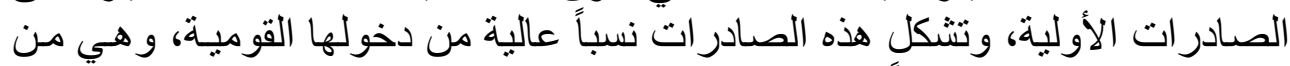

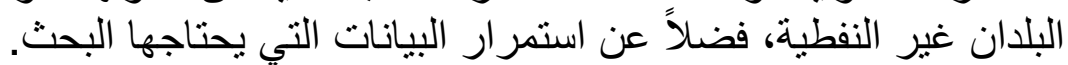

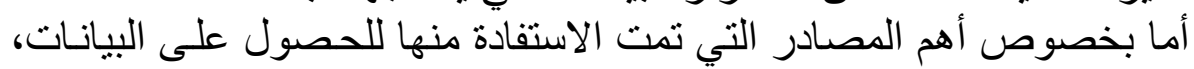

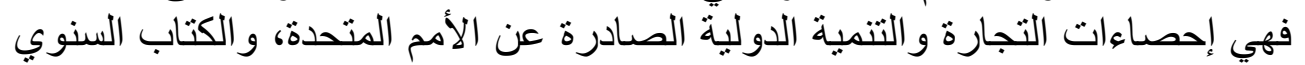

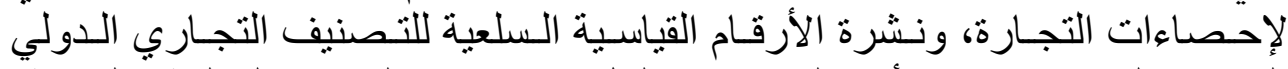

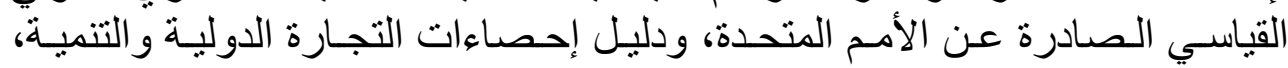
الصادر عن الاونكتاد (UNCTAD).

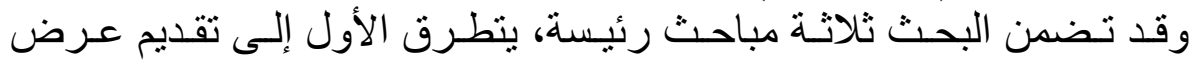

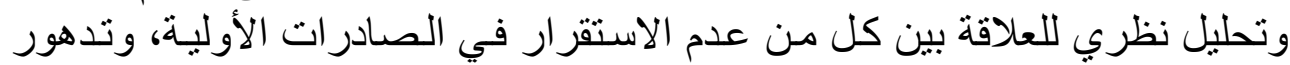

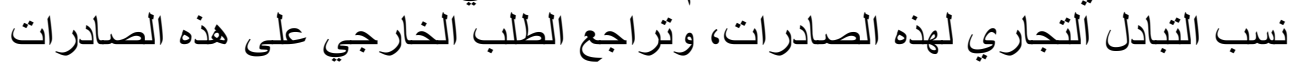
و النمو الاقتصادي. 


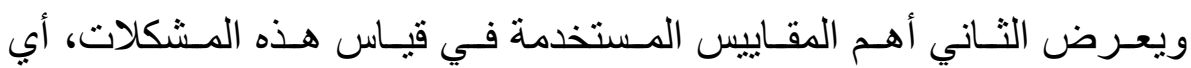
المقاييس المستخدمة في قياس درجة المدي عدم الاستقرار، ونسب التبادل التجاري و الطلب

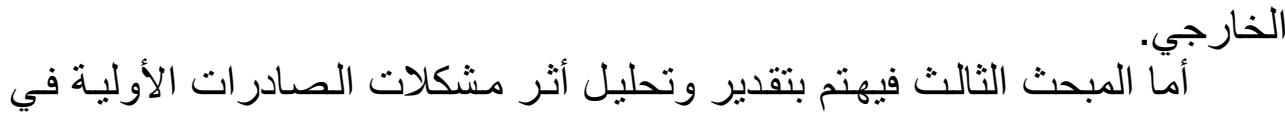

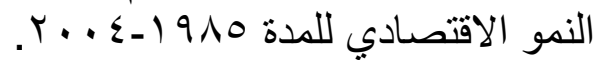
و أهم نتيجة توصل إليها البحث، هي إن زيادة درجة الئه عدم الاستقرار في عوائد

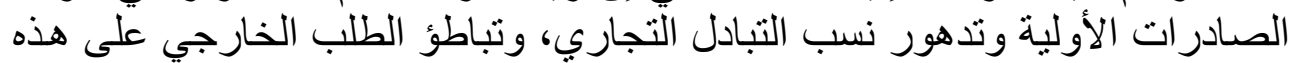

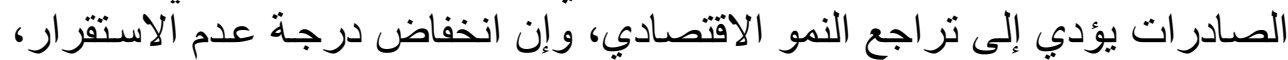

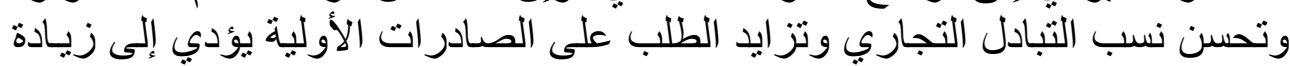

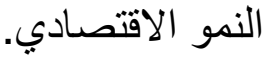

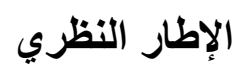

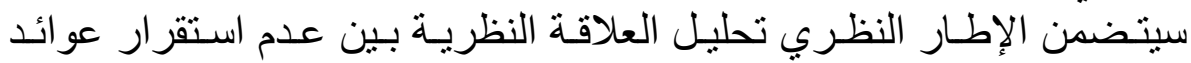

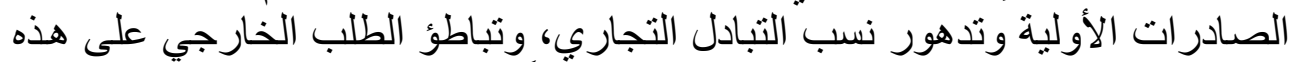
الصادرات و النمو الاقتصادي كل على لنى انفر اد تبأَعاً وكما يأتي:

أولاً عدم استقرار عوائد الصادرات الأولية(*) والنمو الاقتصادي

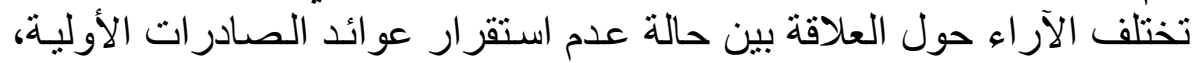

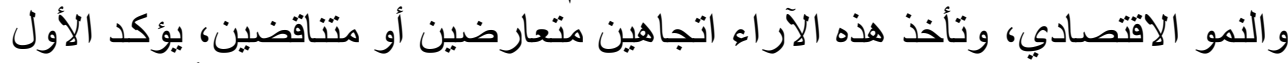

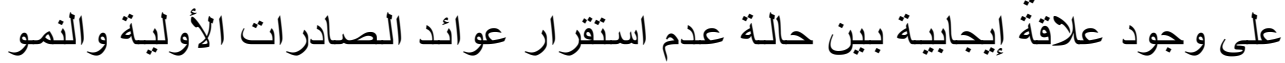

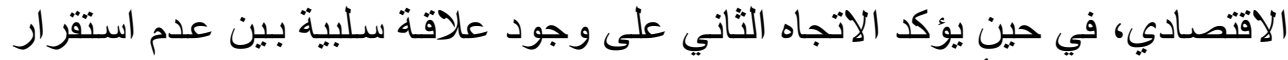
عو ائد الصنادرات الأولية والنمو الاقتصنادي.

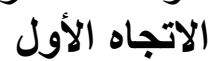

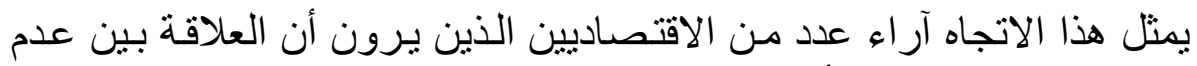

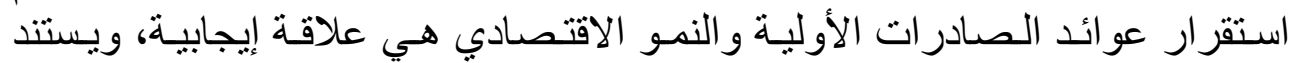

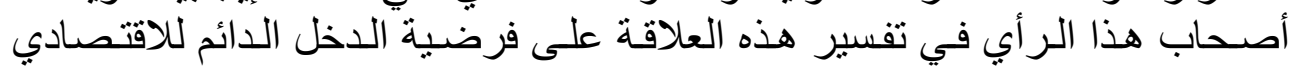

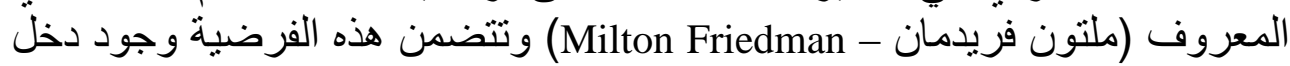

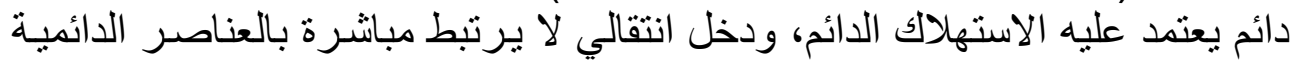

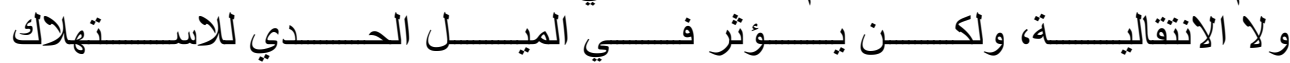
.(Singh, et.al., 1988, 283-304)

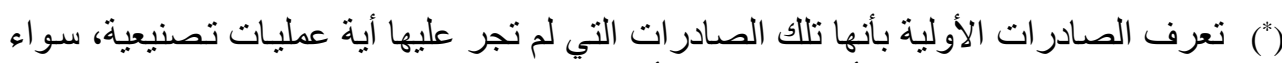

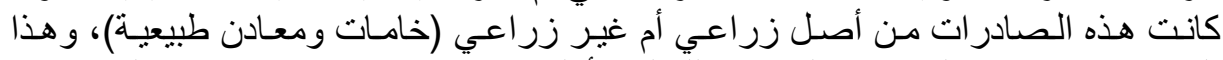

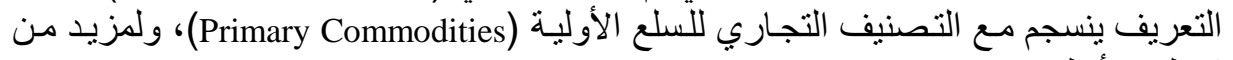
الإطلاع أنظر UNCTAD (2005), "The Standard International Trade Classification Revision 3", 2005. 


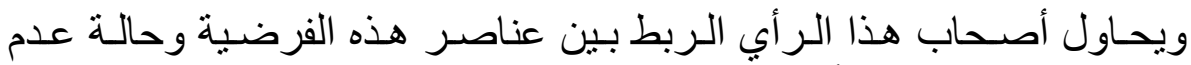

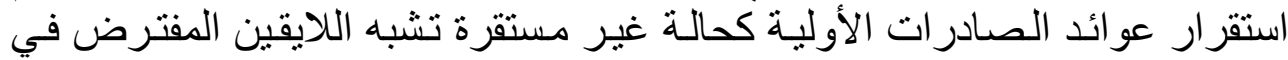

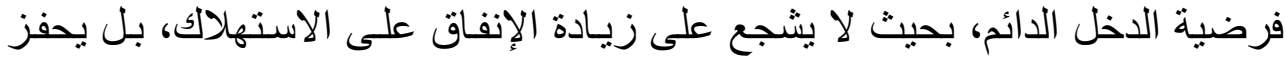

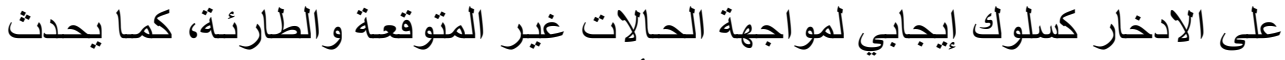

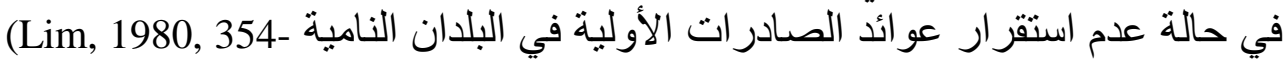

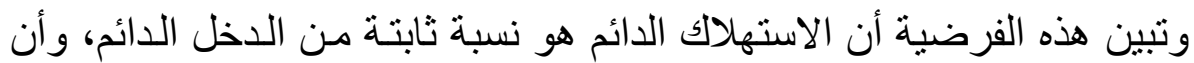

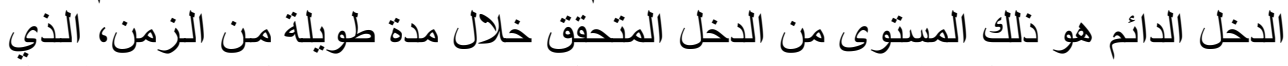

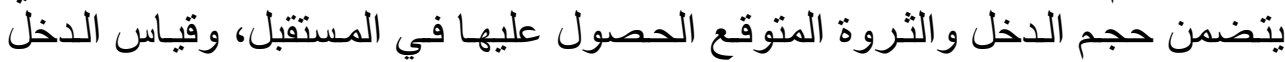

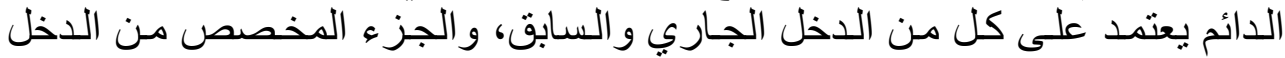

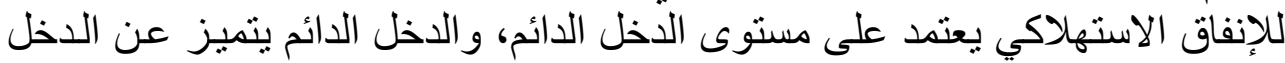

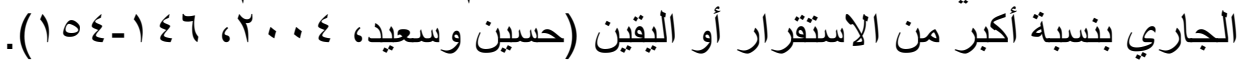
وقد قسم (فريدمان) الاخل الفعلي على عنى الأصرين الفين هما: عنصر دائمي و عنصر انتقالي، أي ان : $\mathrm{Y}=\mathrm{y}^{\mathrm{p}}+\mathrm{y}^{\mathrm{t}} \ldots \ldots \ldots \ldots \ldots . . .1$

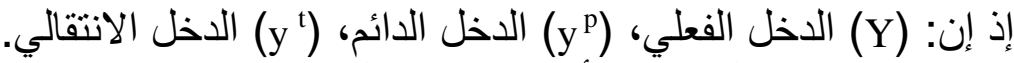

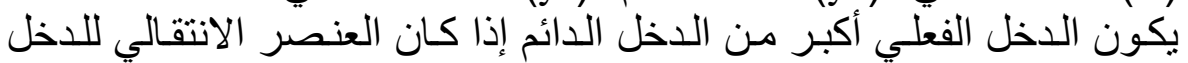

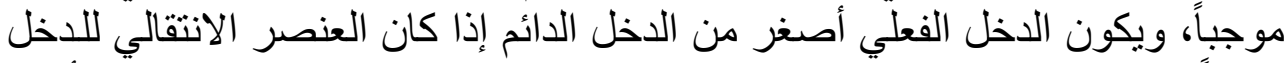

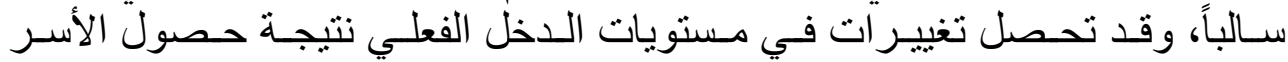

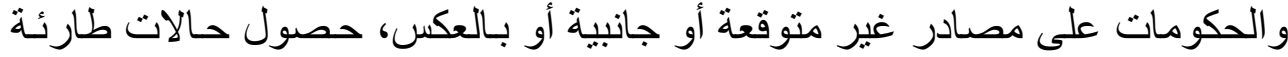

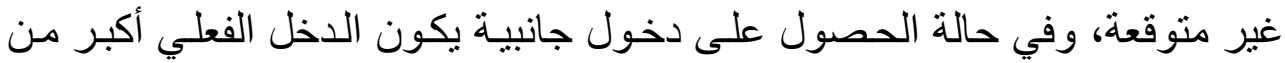

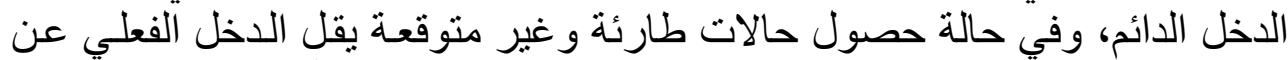

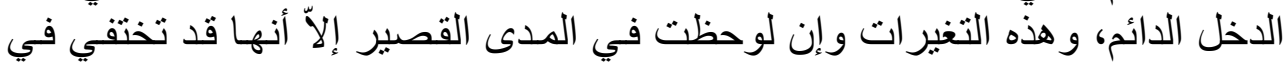

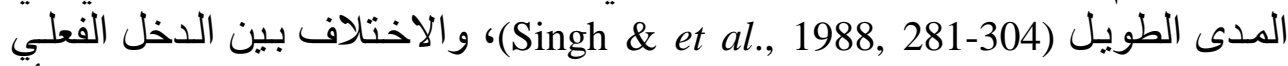

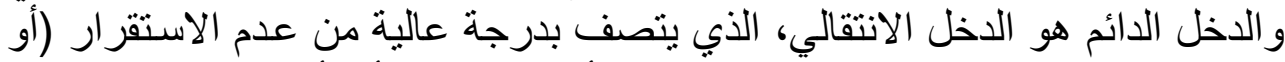

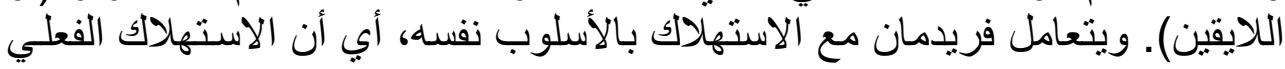

$$
\mathrm{C}=\mathrm{C}^{\mathrm{p}}+\mathrm{C}^{\mathrm{t}} \ldots \ldots \ldots \ldots . .2
$$

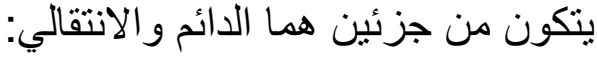

$$
\text { إذ إذ : (c) }
$$

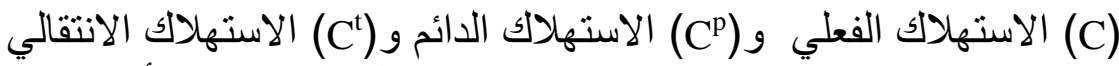

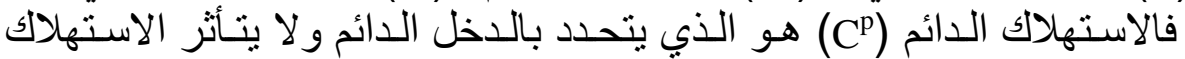

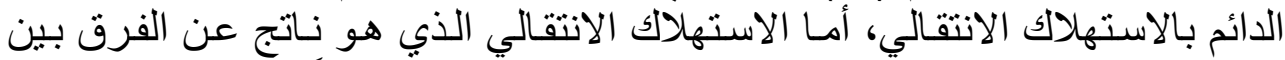

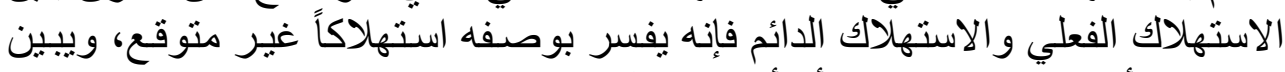

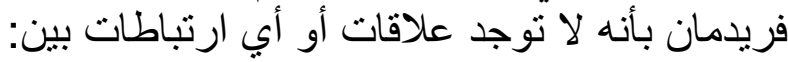

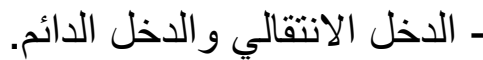
ـ الاستهلاك الانتقالي و الاستهلاك الأل الدائم. 
ـ الدخل الانتقالي و الاستهلاك الانتقالي.

$P\left(y^{p}, y^{t}\right)=P\left(C^{p}, C^{t}\right)=P\left(y^{t}, C^{t}\right)=0 \ldots \ldots \ldots . .3$

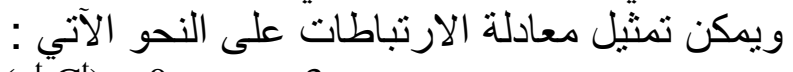

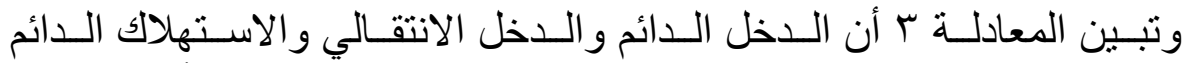

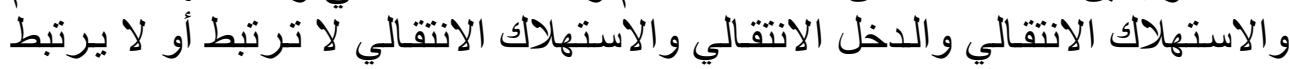

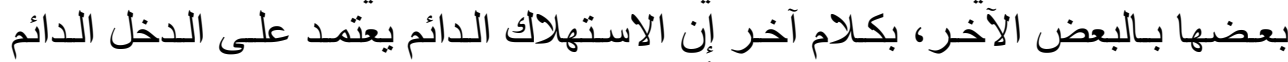
$\mathrm{C}^{\mathrm{P}}+\mathrm{K} \mathrm{Y}^{\mathrm{P}}$

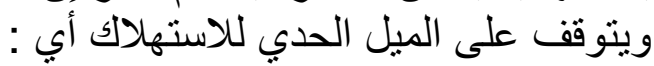

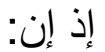

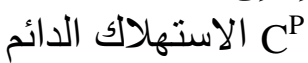

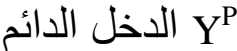

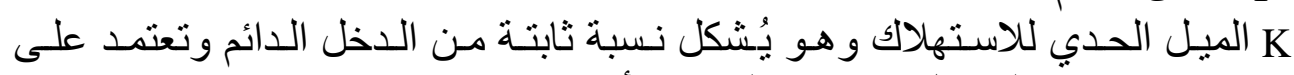
$\mathrm{C}^{\mathrm{P}}=\mathrm{K}(\mathrm{I}, \mathrm{W}, \mathrm{U}) \mathrm{Y}^{\mathrm{P}}$

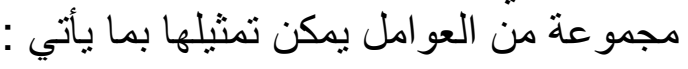

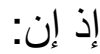

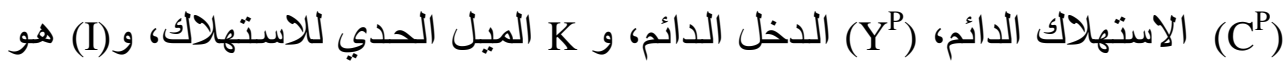

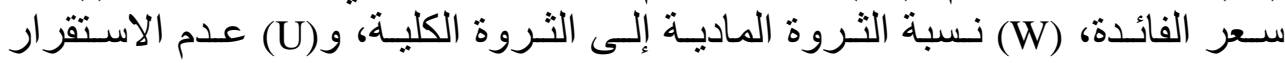

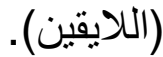

إن ارتفاع مستوى عدم الاستقر ار أو اللايقين المتمثل بـ (U) يؤدي إلى الـى تحفيز

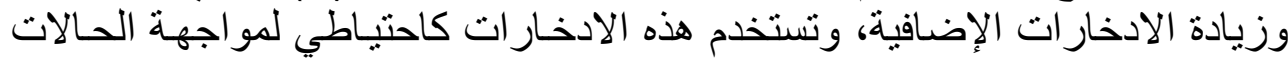

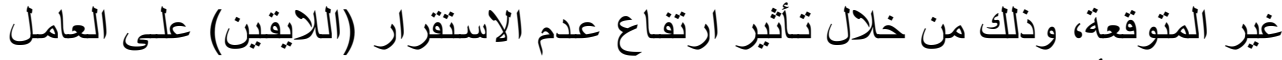

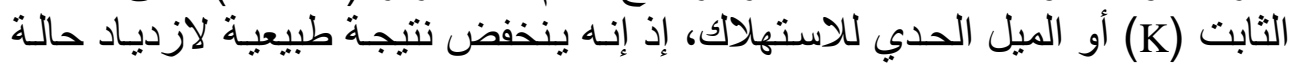

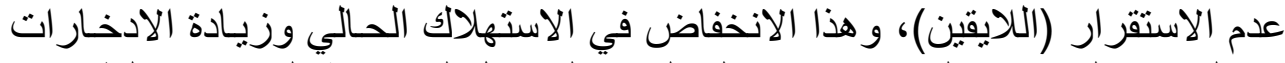

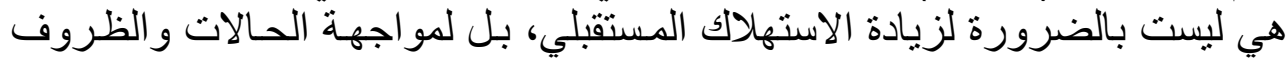

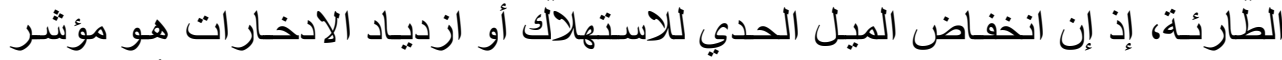

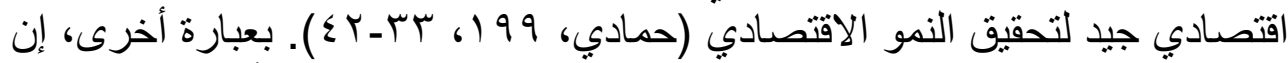

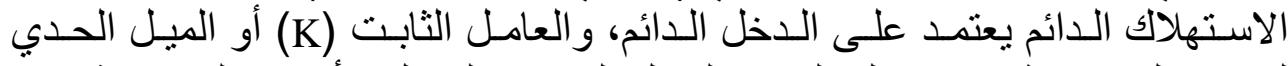

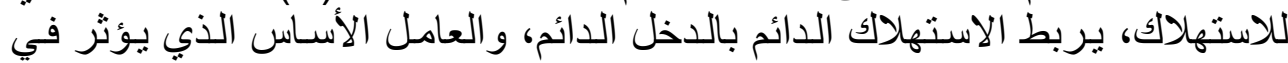

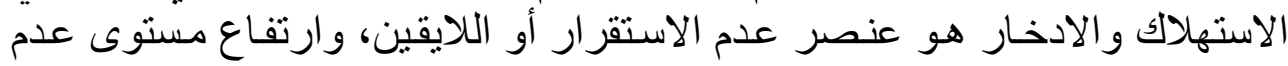

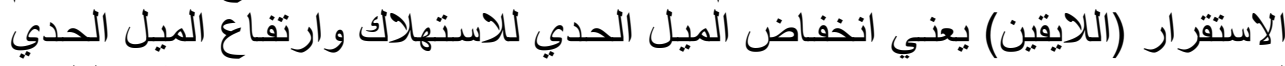

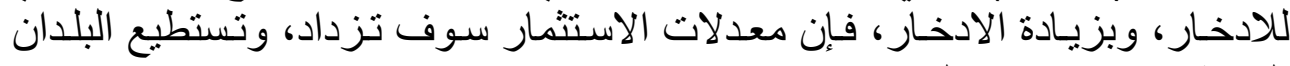

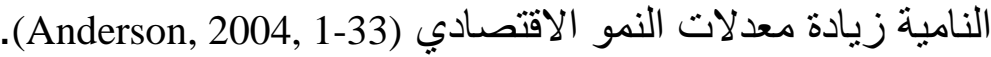

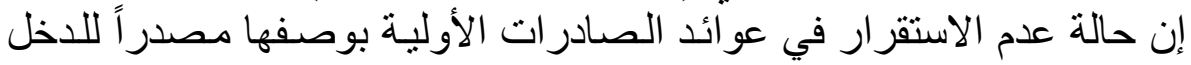
مشابه لحالة اللايقين في فرضية الدخل الدائم لفريدمان، إذ إن العوائد الداند الدستحصلة من 


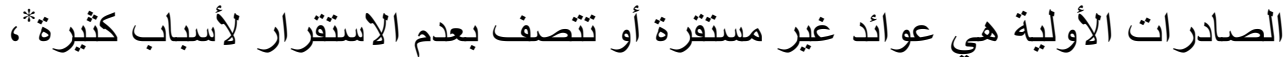

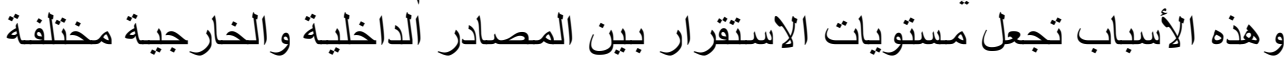

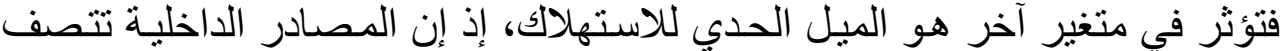

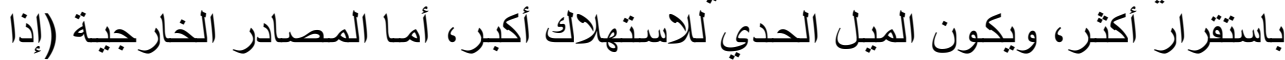

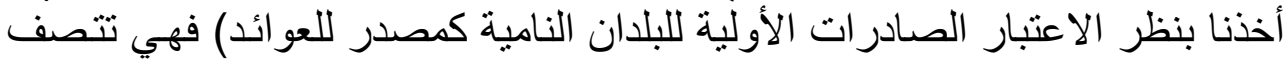

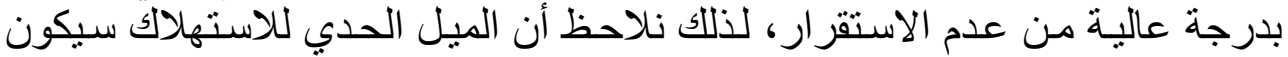

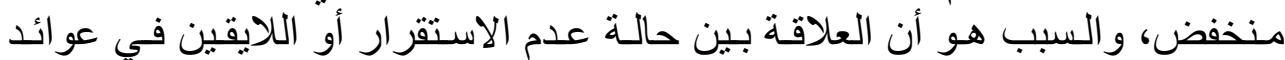

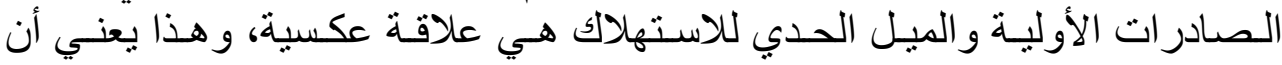

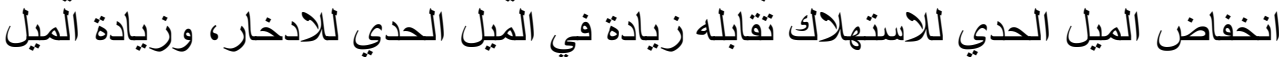

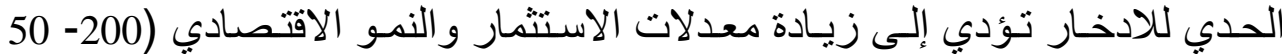
.(UNCTAD, 2005,

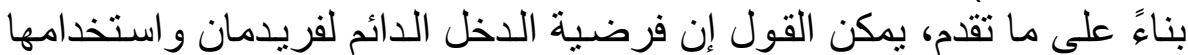

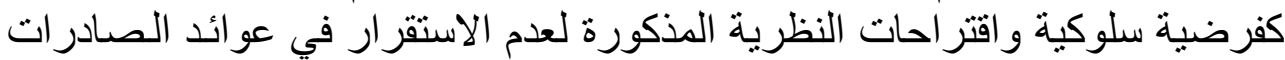

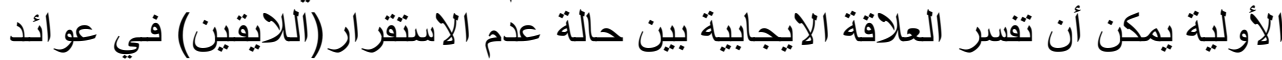

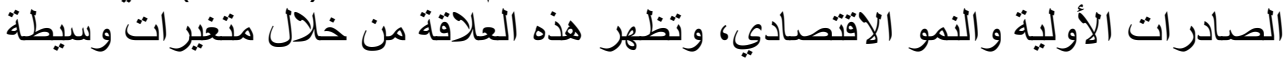

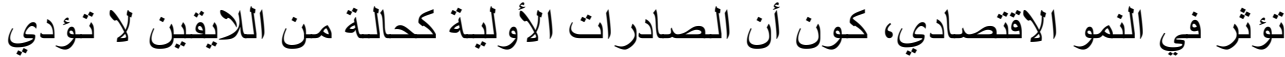

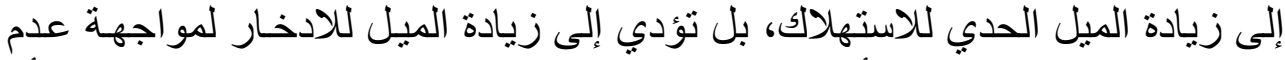

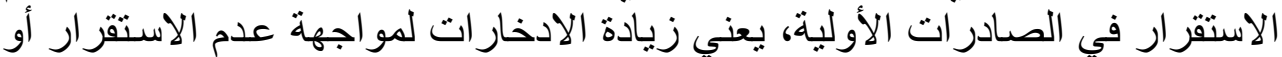

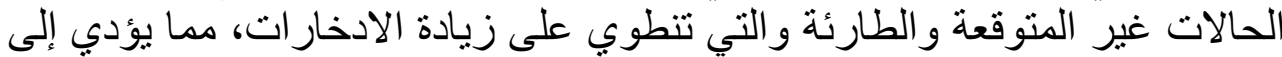

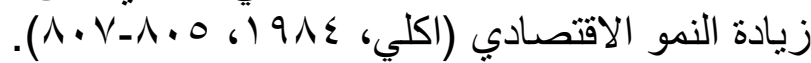

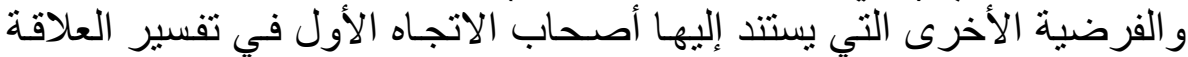

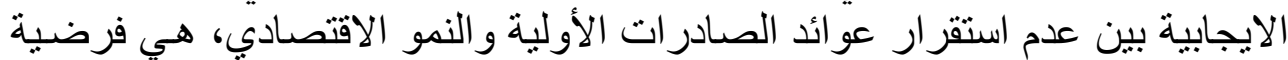

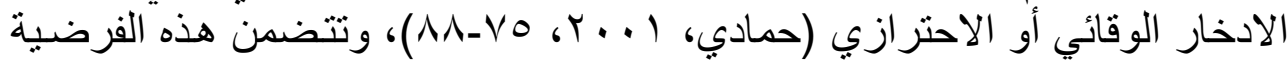

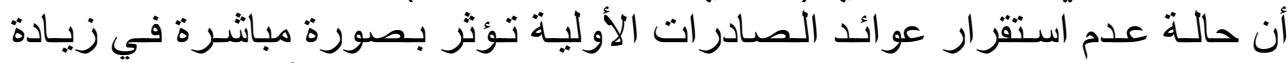
مستويات الطلب على الادخار في الاقتصاد، وذللك كإجر اء وقائي أو احتياطي.

$$
\text { * من العوامل التي تسبب حالة عدم الاستقر ار: }
$$

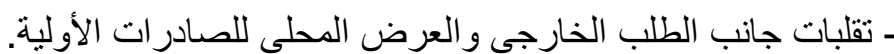

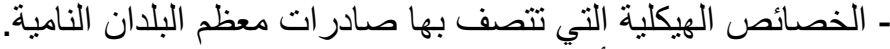

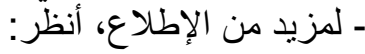

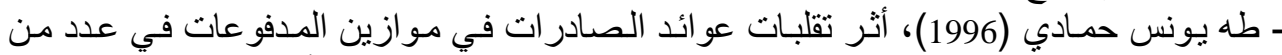

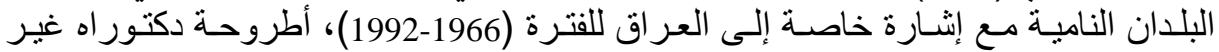

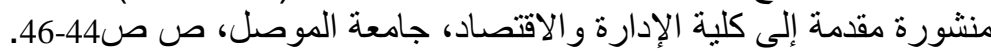

- MacBean , A., (1964), " Causes of Excessive Flactuations in Export Proceeds of Underdeveloped Countries ", pp323-341.

- United Nations (2005), " World Economic and Social Survey 2005 Financing for Development " , department of Economic and social Affairs New York, 2005 


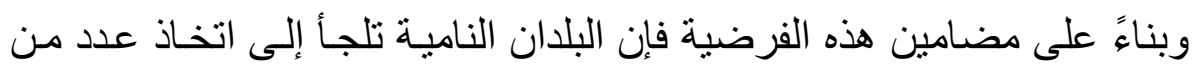

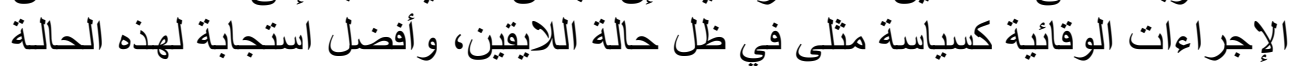

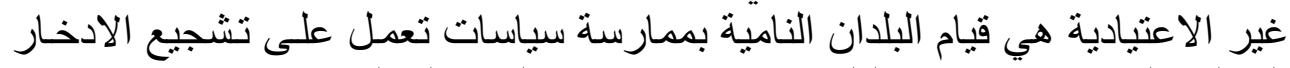

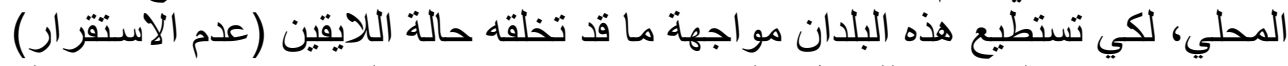

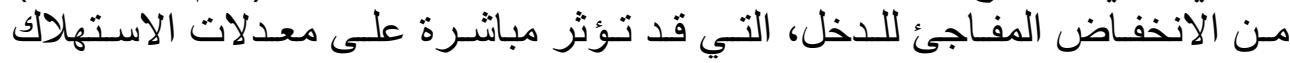
و الادخار ، ومن ثم النمو الاقتصادي.

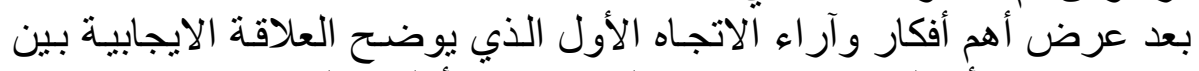

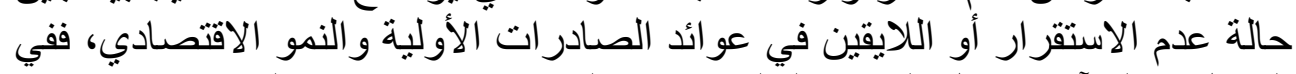

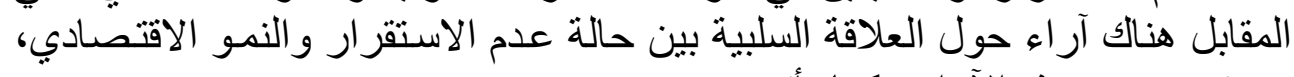
وسيتم عرض هذه الآراء وكما يأتي:

الاتجاه الثاني - الآراء التي تؤكد العلاقة السلبية

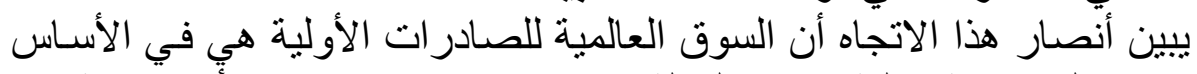

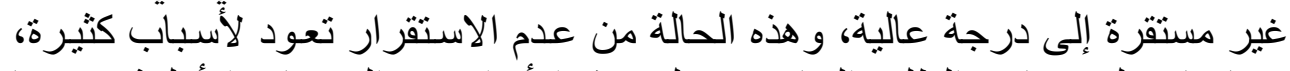

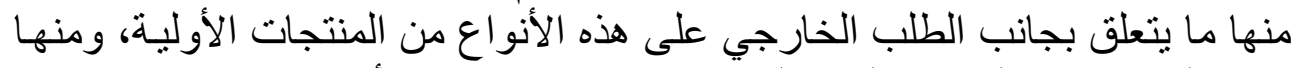

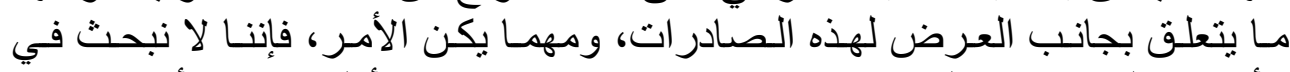

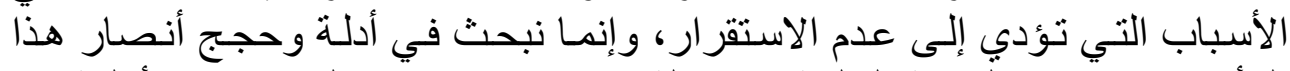

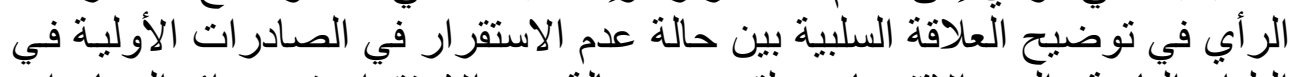

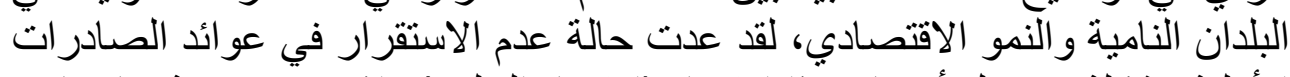

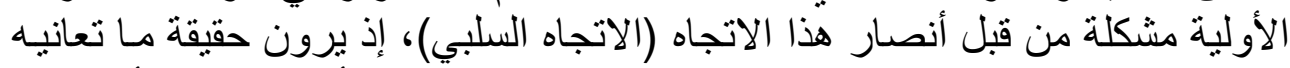

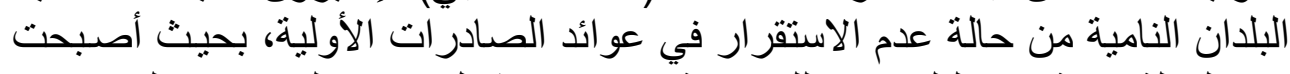

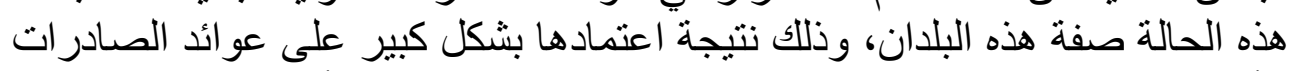

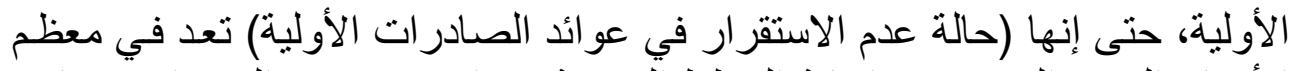

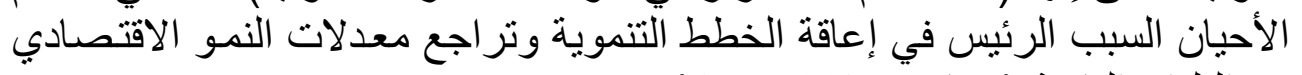

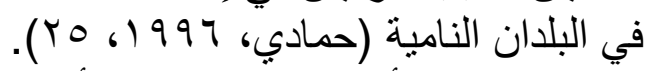

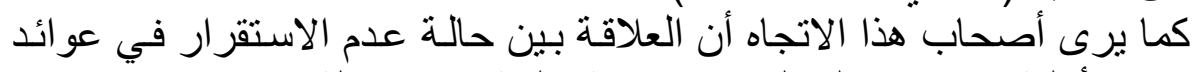

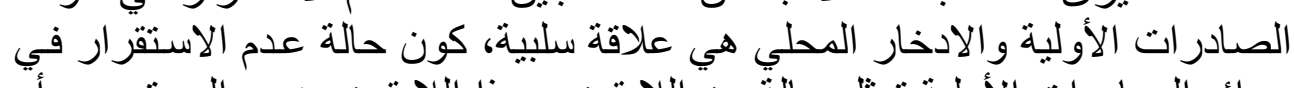

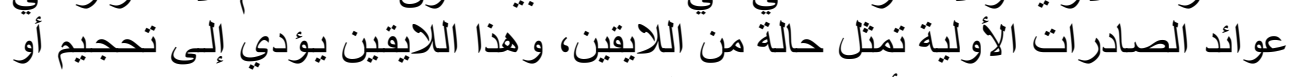

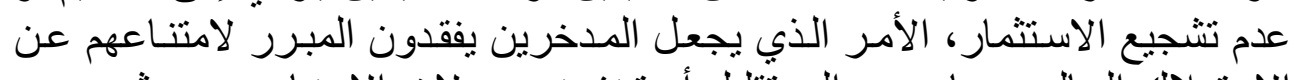

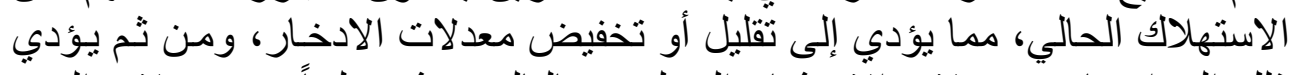

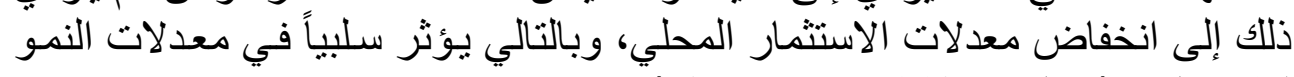

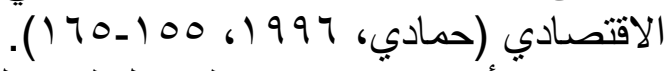

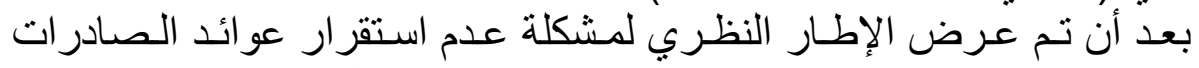

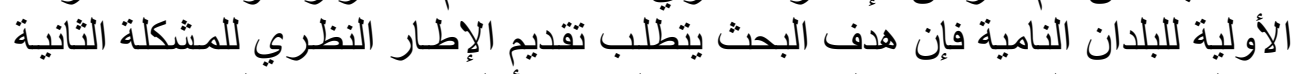

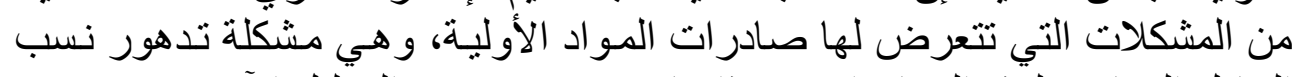

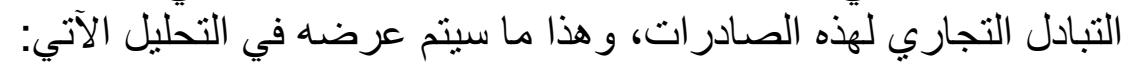


ثانياً- تدهور نسب التبادل التجاري للصادرات الأولية والنمو الاقتصادي

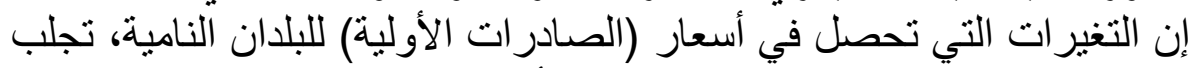

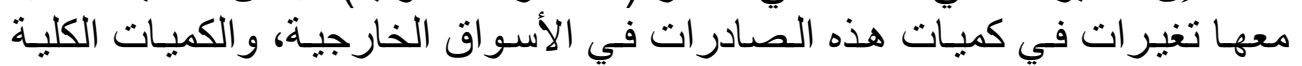

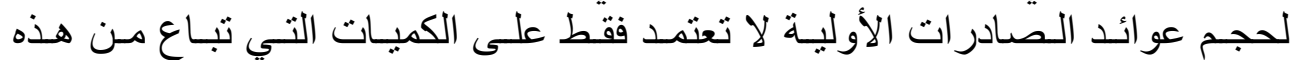

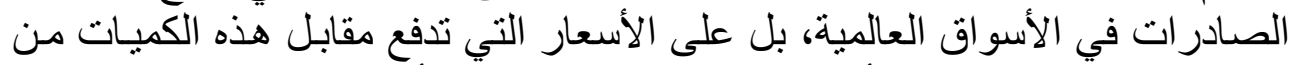

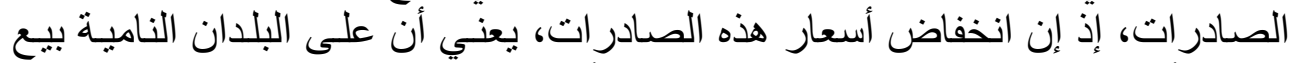

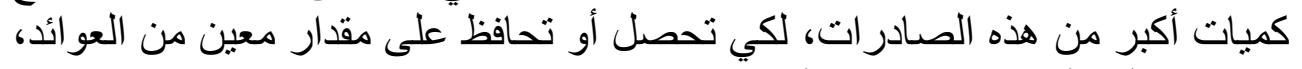

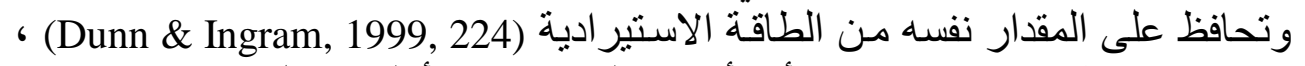

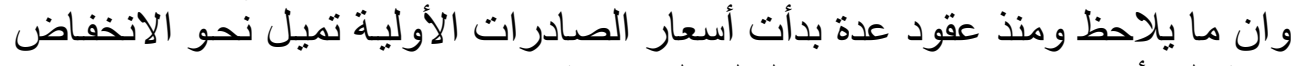

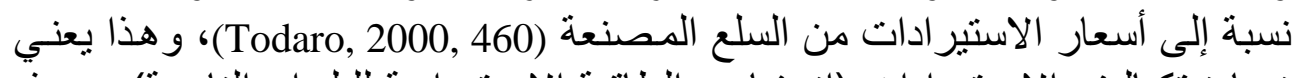

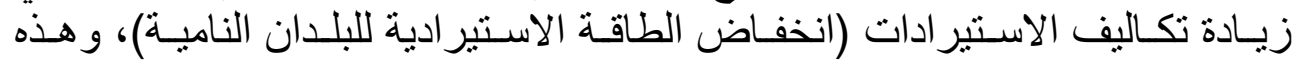

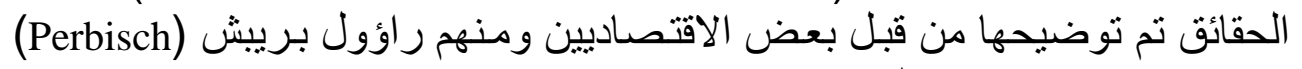

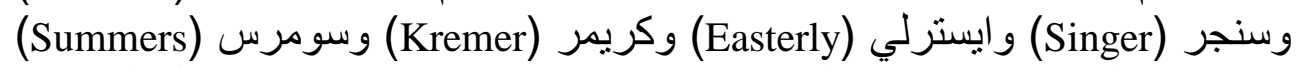

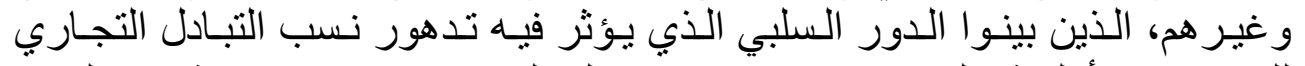

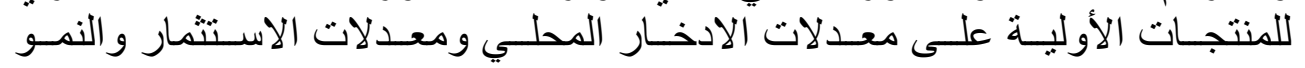

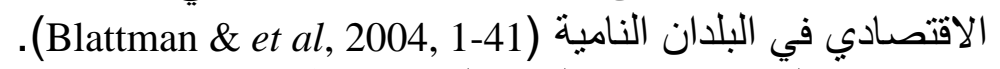

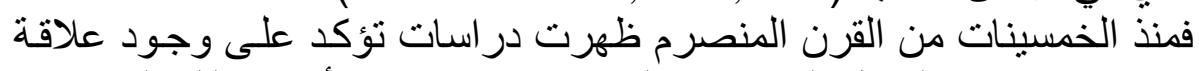

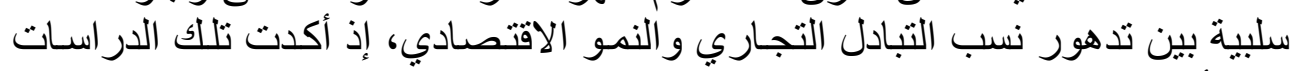

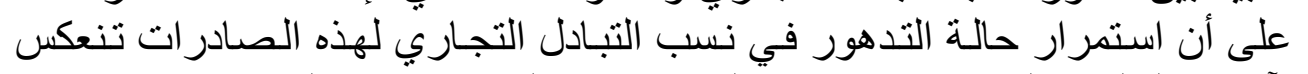

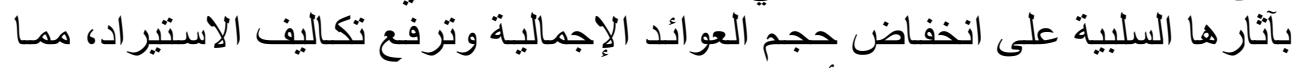

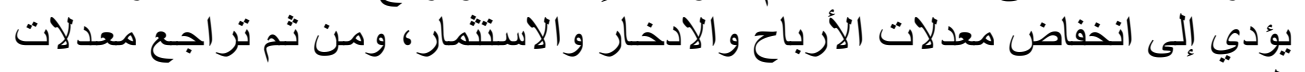
النمو الاقتصادي (Lipesey, 1994, 1-32).

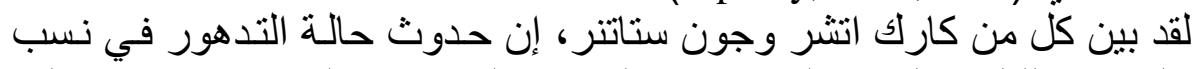

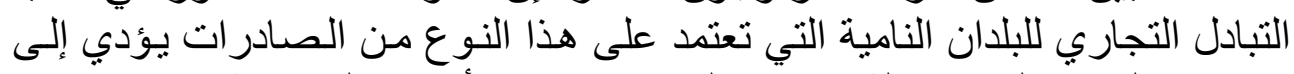

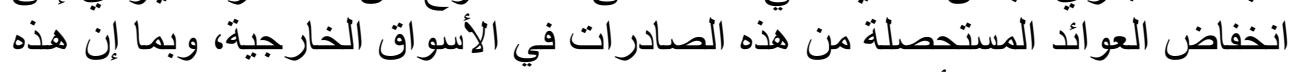

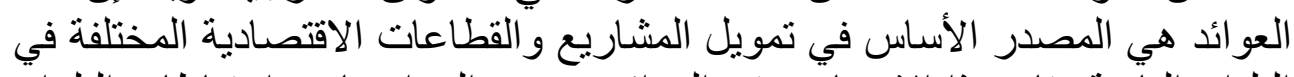

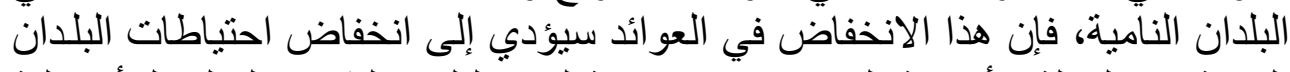

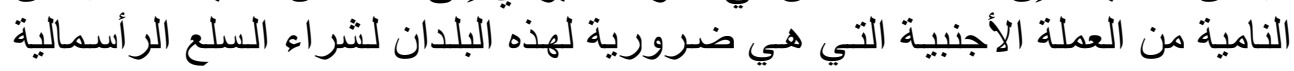

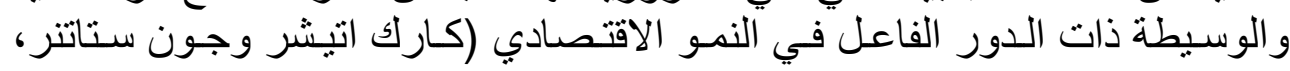
(VY-V・ 6) 919

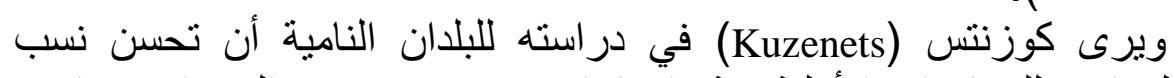

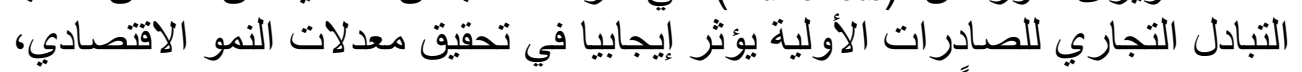

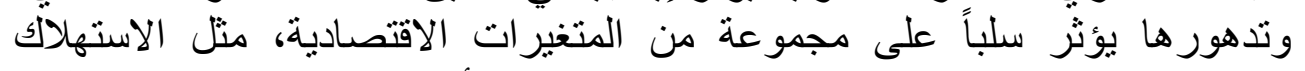

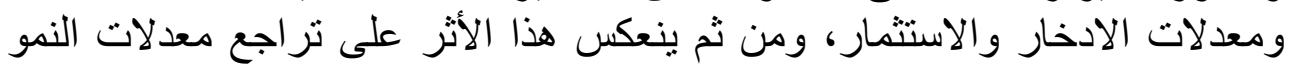

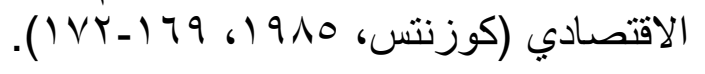




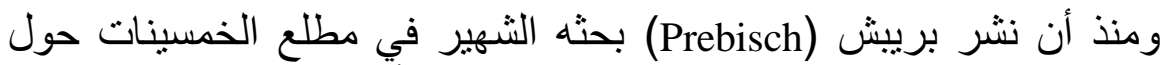

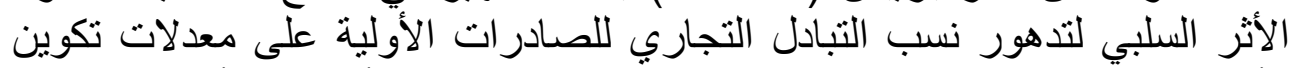

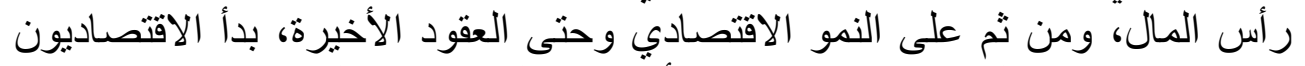

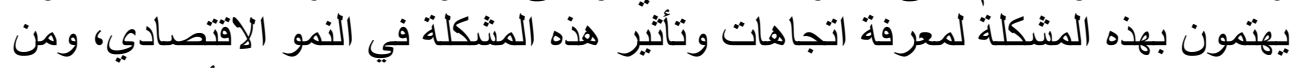

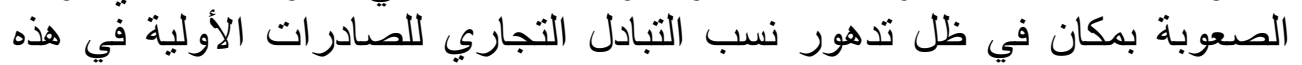

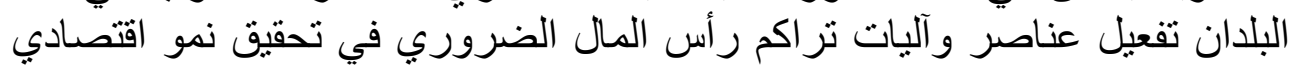
(Hyman, 1994, 485-486)

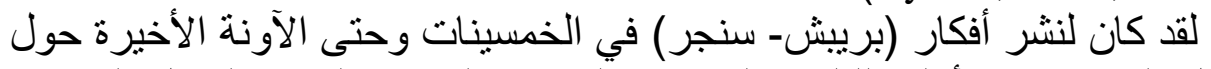

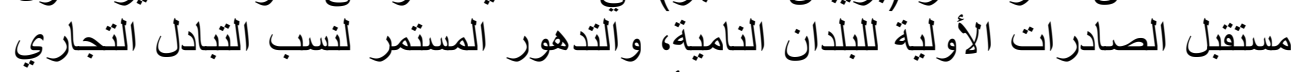

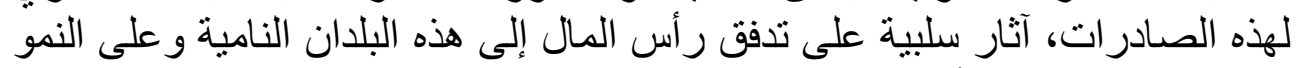

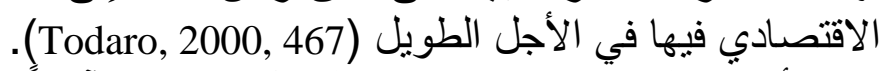

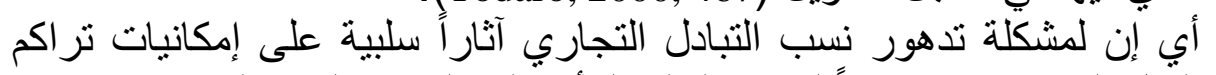

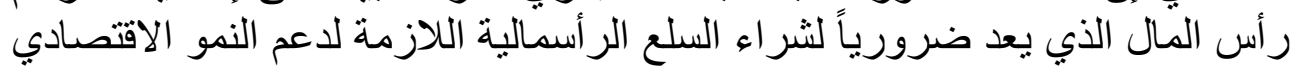
(UNCTAD, 2006, 1-25) إن العلاقة الموجودة بين نسب التبادل التجاري للصادرات ومعدلات الادخار

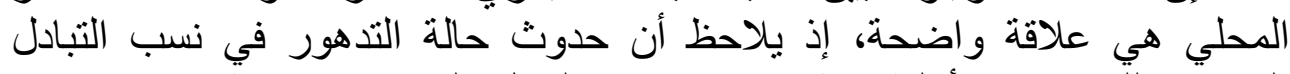

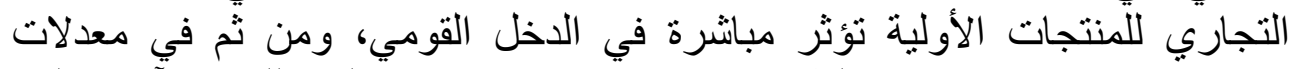

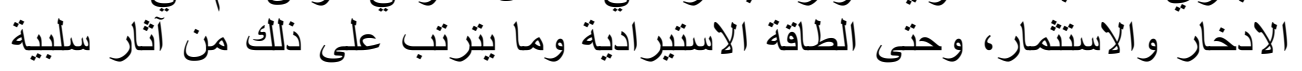

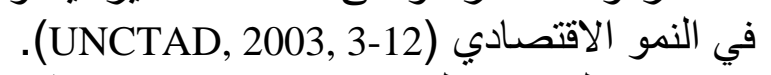

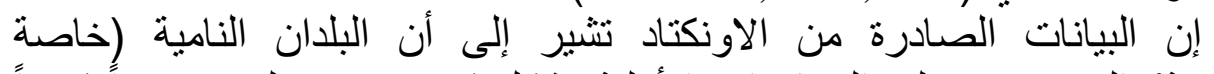

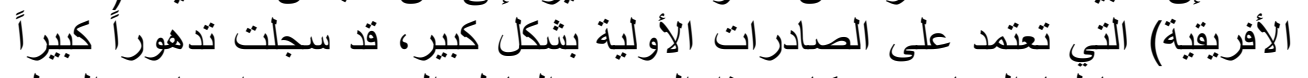

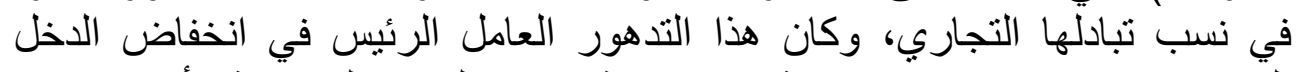

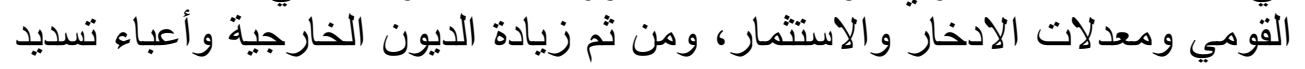

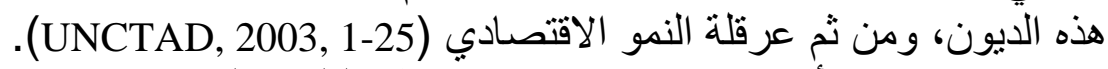

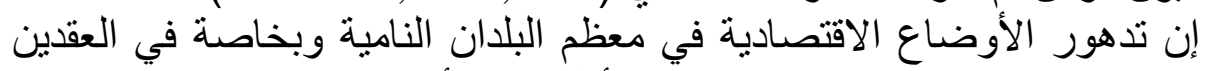

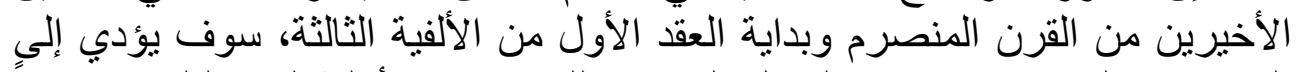

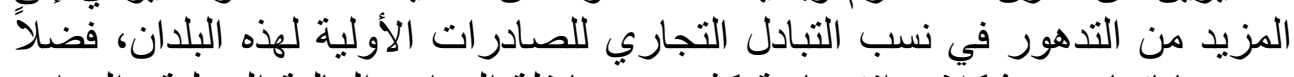

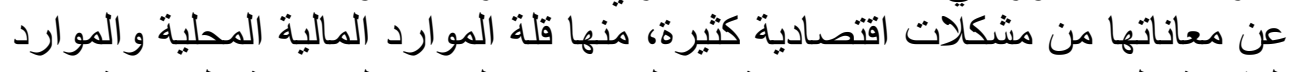

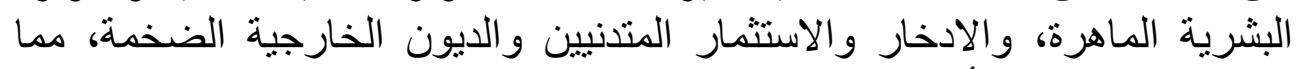

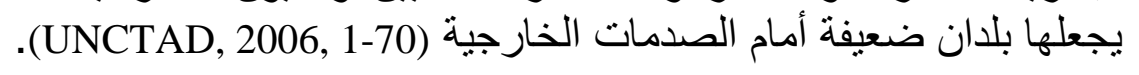

ثالثاً. العلاقة بين تباطؤ الطلب الخارجي على الصادرات الأولية والنمو الاقتصادي

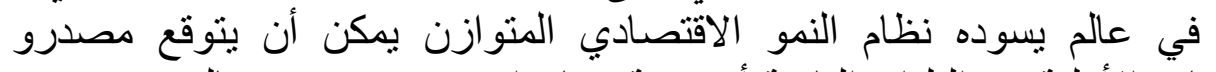

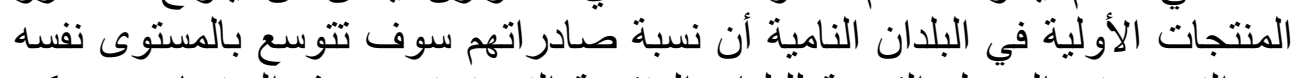

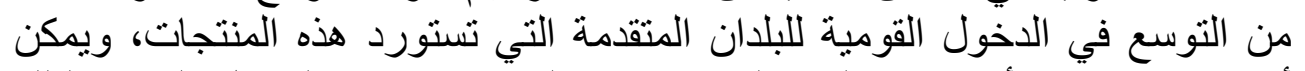

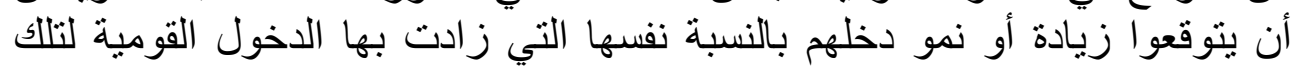


البلدان (Gillis, et. al., 1987, 418)، ويتطلب نمو الدخل القومي للبلدان النامية

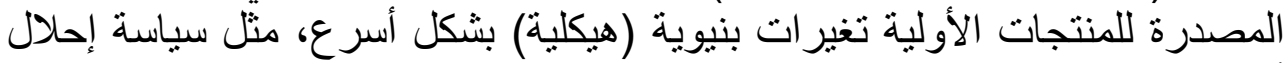

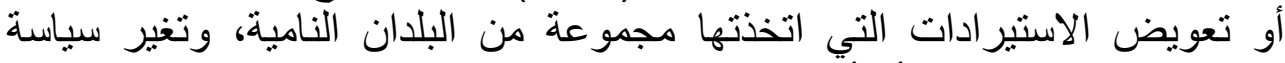

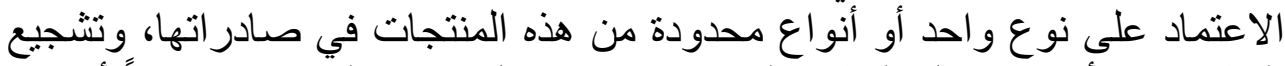

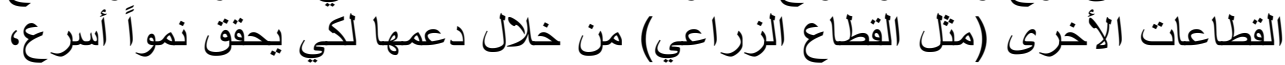

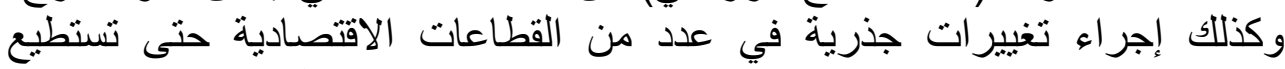

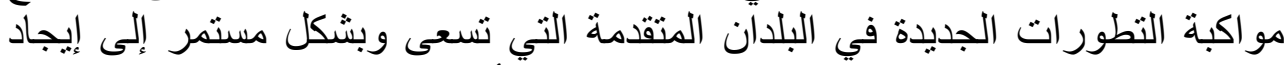

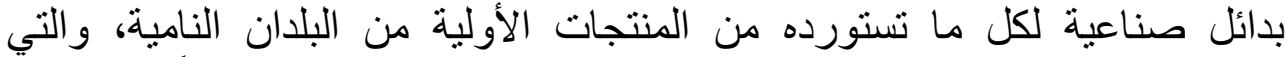

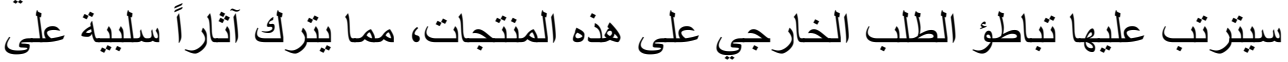

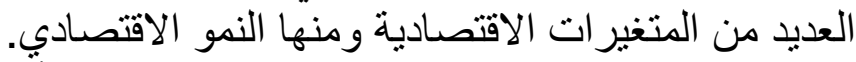

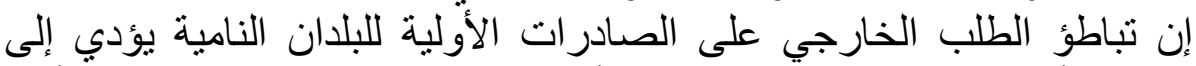

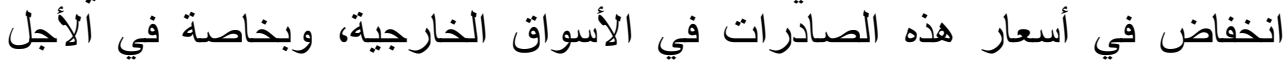

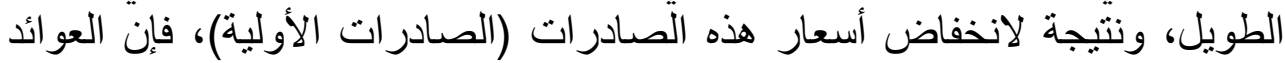

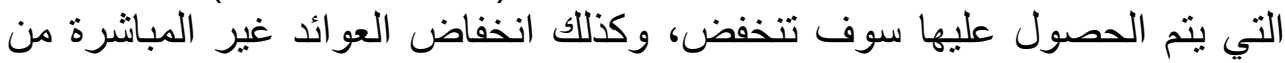

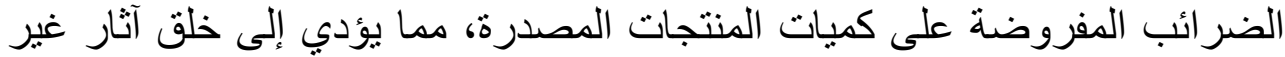

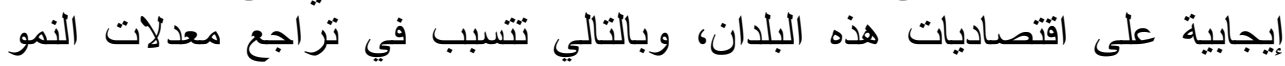
الاقتصادي في هذه البلدان (Daniel \& Lever, 1998, 246-247).

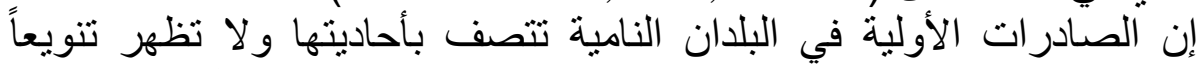

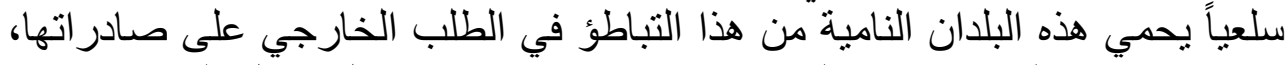

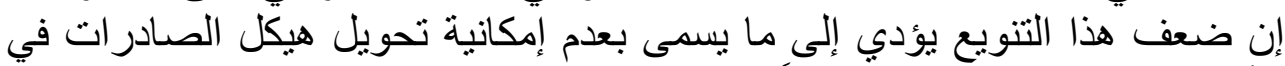

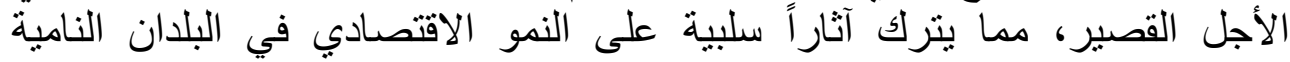

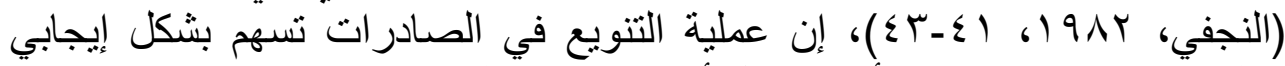

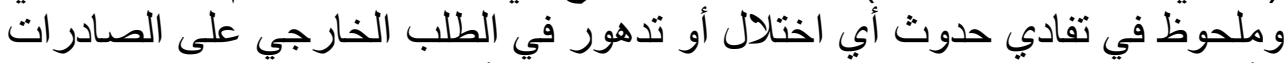

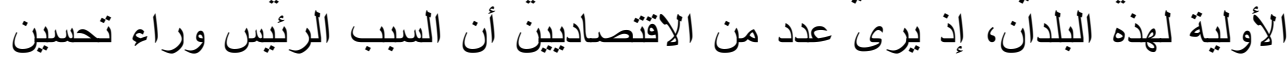

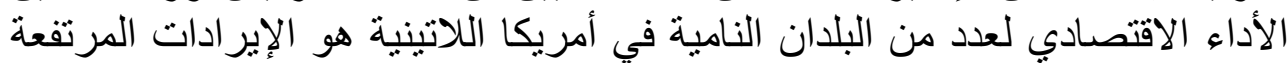

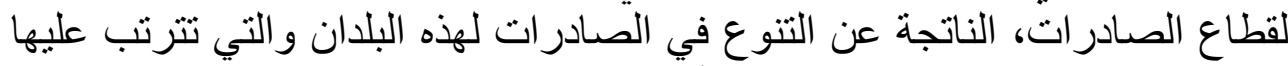

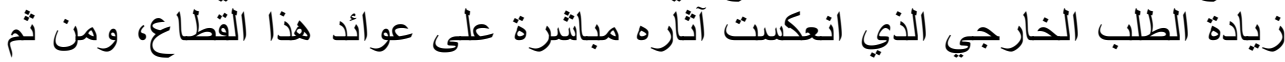
على مستويات الدخل ومعدلات الادخار و الاستثمار و النمو الاقتصادي النادي في هذه البلدان

.(Gottschalk \& Prates, 2006, 1-26)

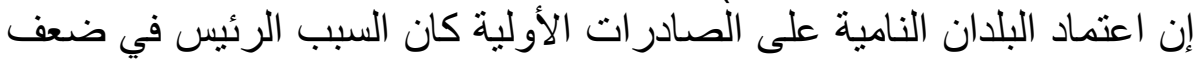

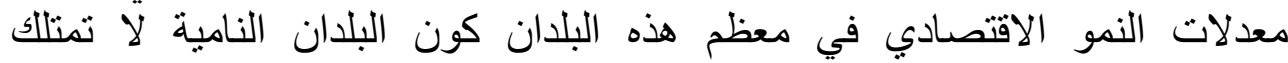

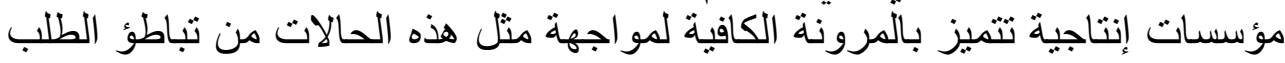

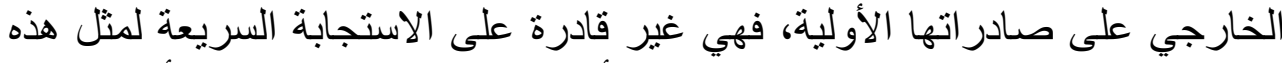

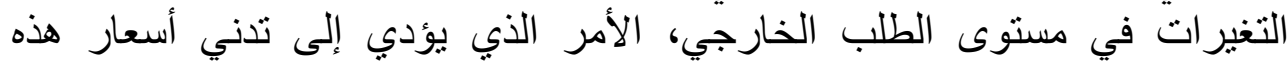

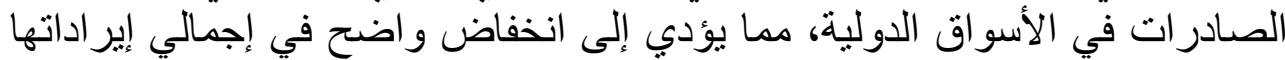

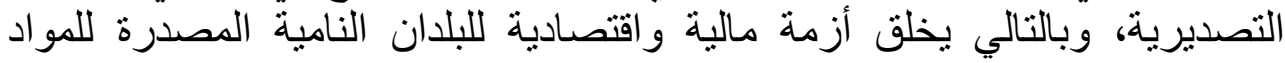


الأولية، نؤثر سلباً على البرامج التنموية المستهدفة في هذه البلدان لتحقيق معدلات عالية من النمو الاقتصادي (Salvatore, 2004, 356-357).

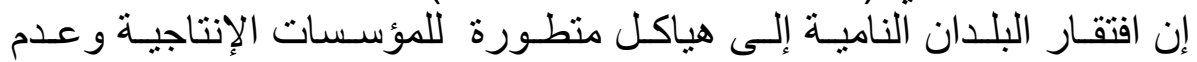

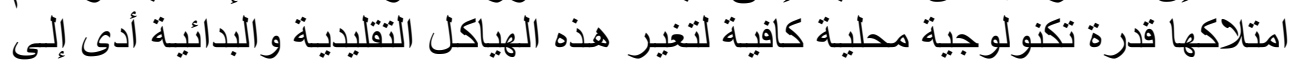

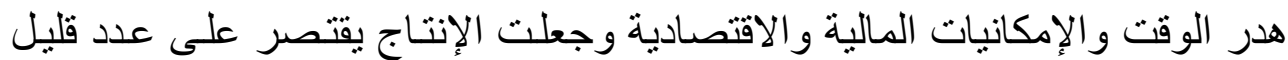

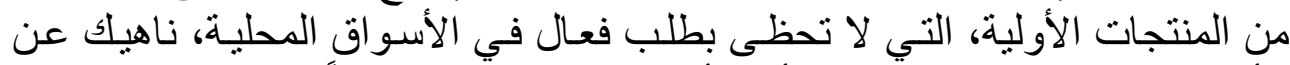

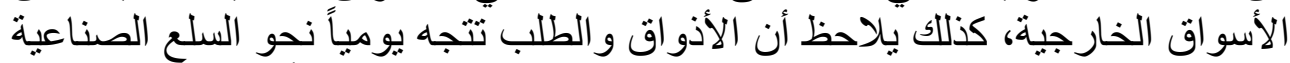

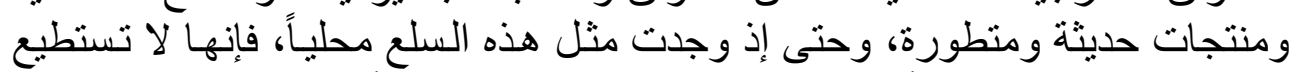

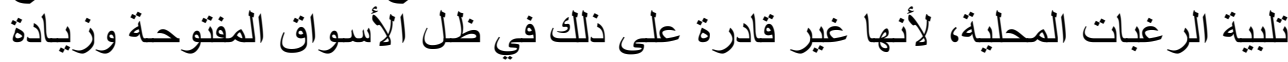

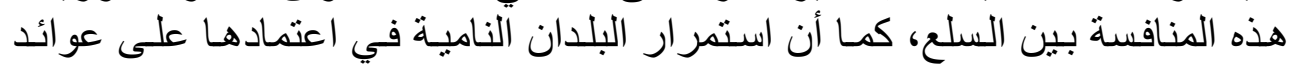

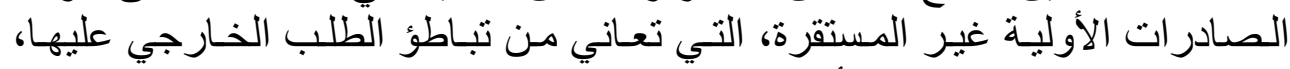

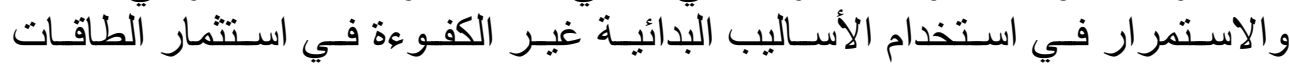

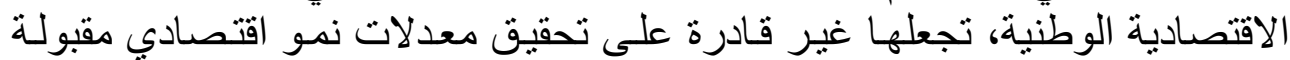

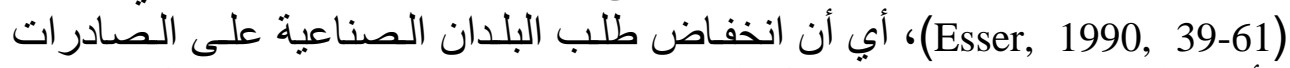

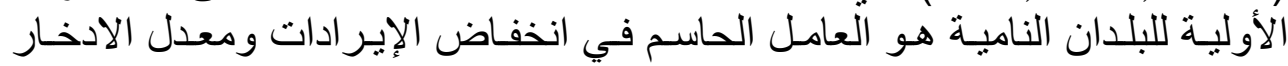

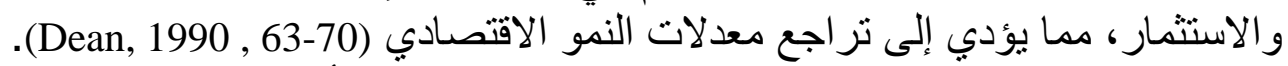

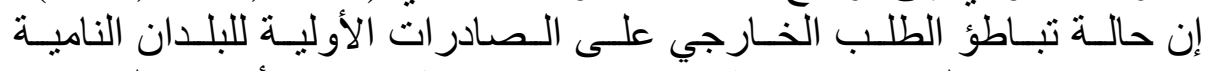

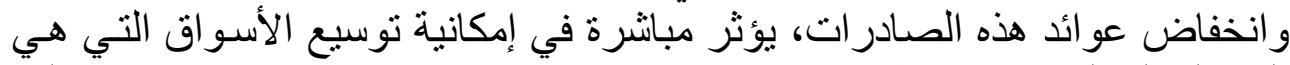

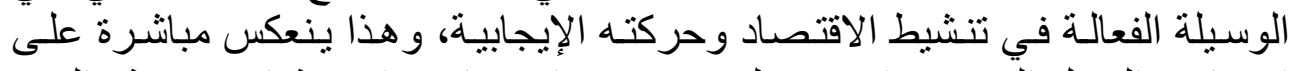

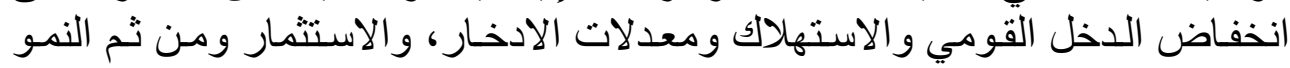

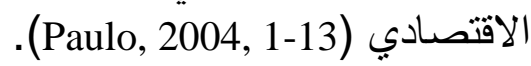

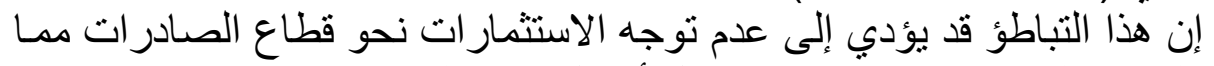

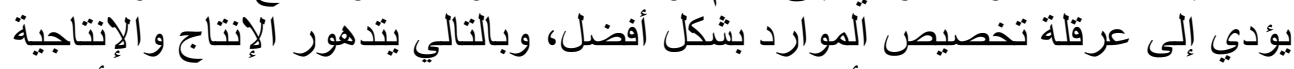

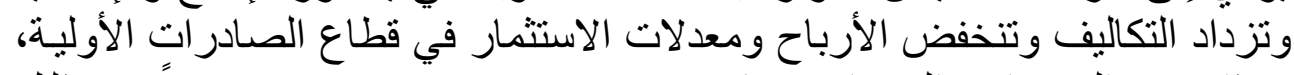

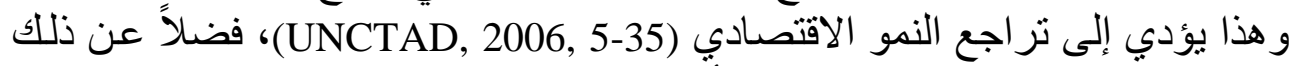

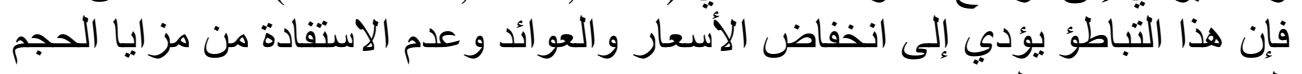

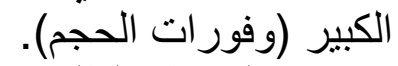

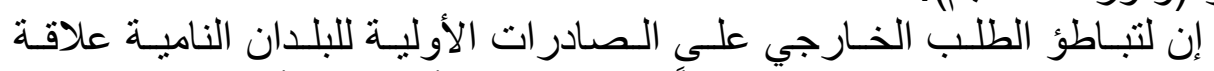

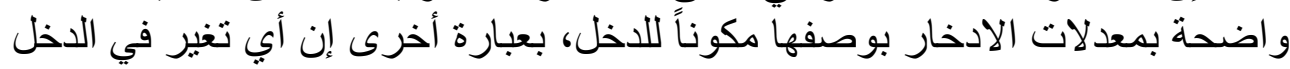

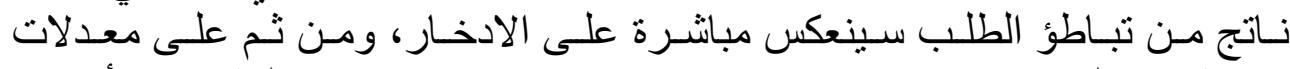

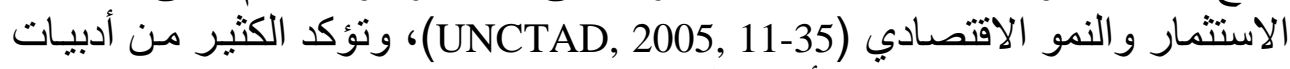

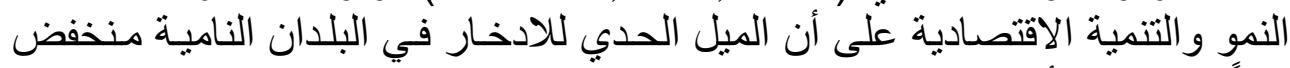

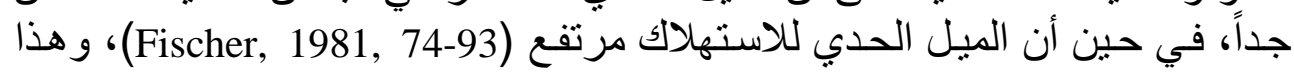

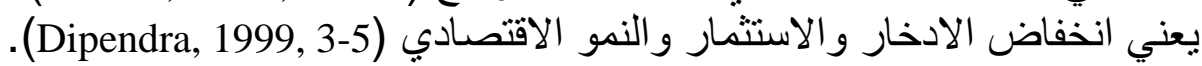

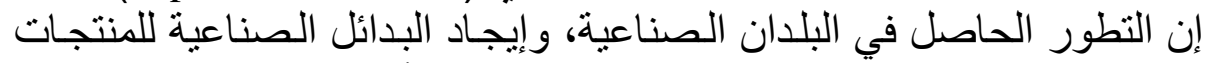

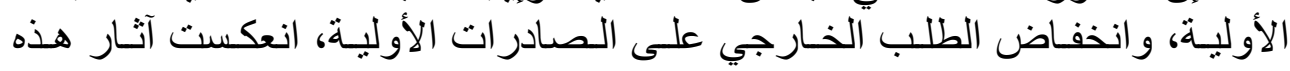




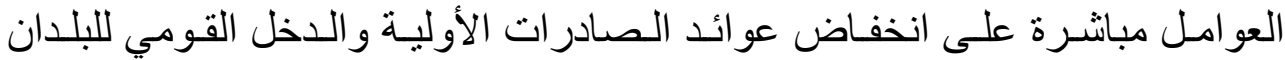

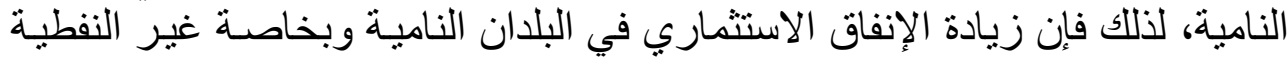

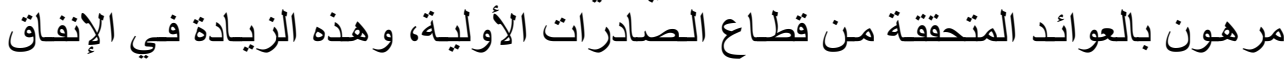

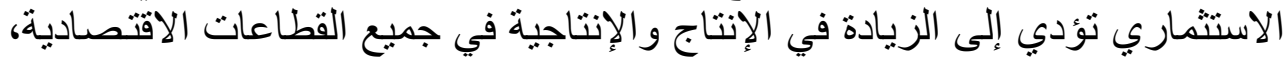

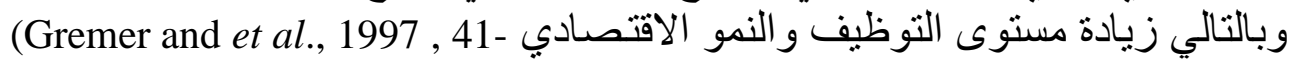

إن دراسات الاتجاه العام للطلب على المواد الأولية التي تصدر ها البلدان النامية

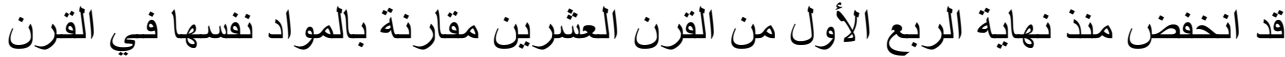

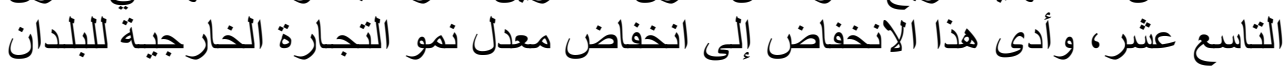

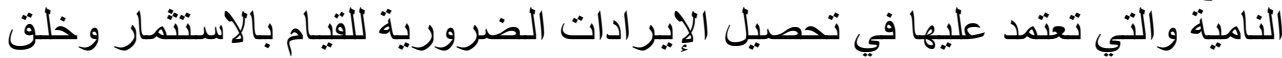

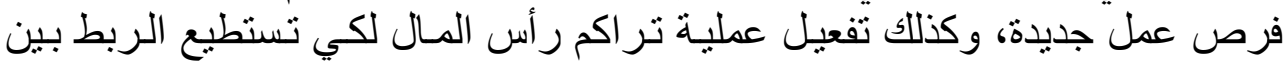

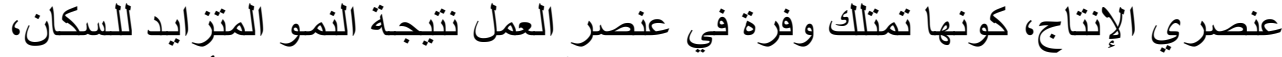

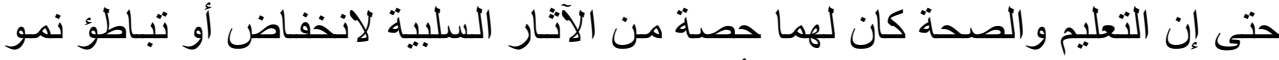

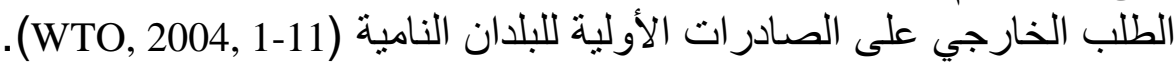

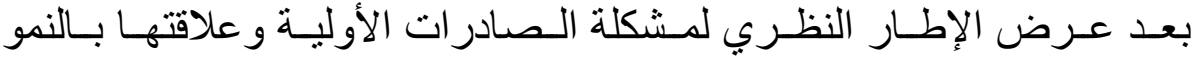

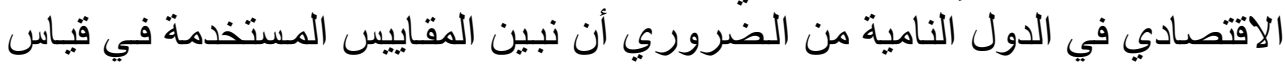

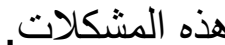

المقاييس المستخدمة في قياس مشكلات الصادرات الأولية أولاً- المقاييس المستخدمة في قياس مشكلة عدم استقرار عوائد الصادرات الأولية على الرغم من اختلاف وتتوع المقاييس و المعايير المستخدمة في قياس حالة

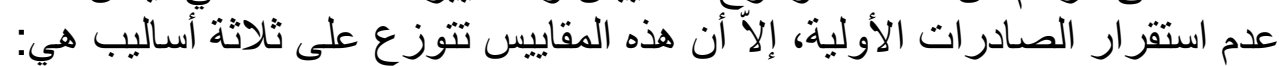
الأول: الأسلوب المعياري أو القياسي. الثاني: الأسلوب المعتمد على مفهوم اللايقين.

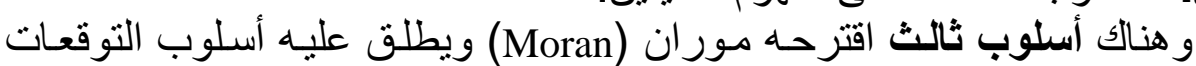

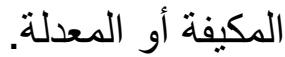

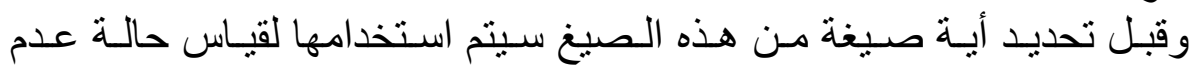

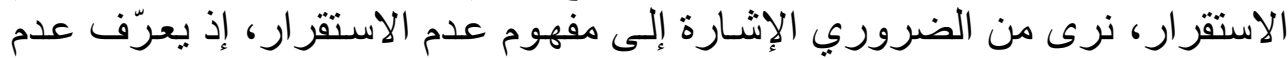

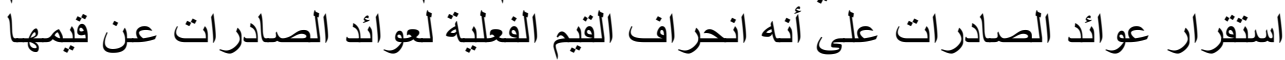
المقدرة أو الاعتيادية (Love, 1985, 246). 


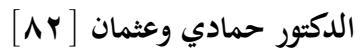

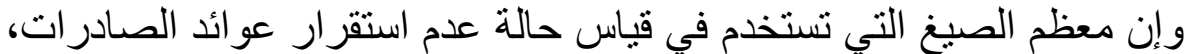

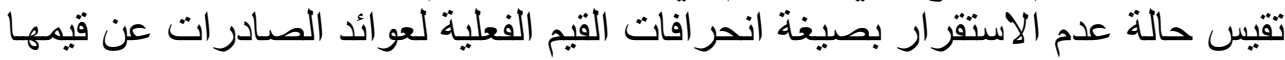

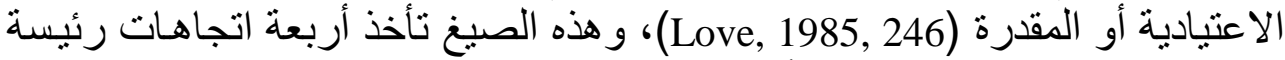

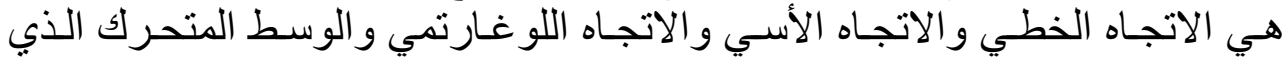

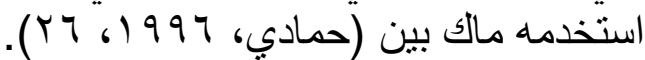

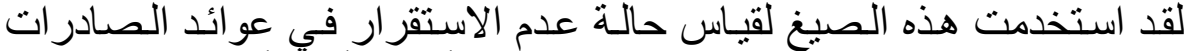

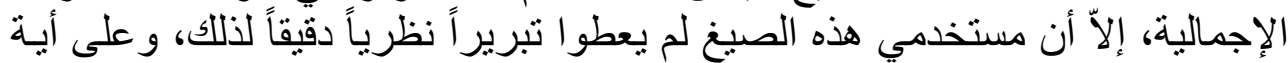

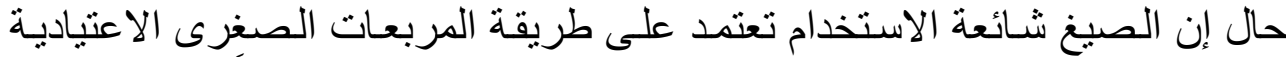

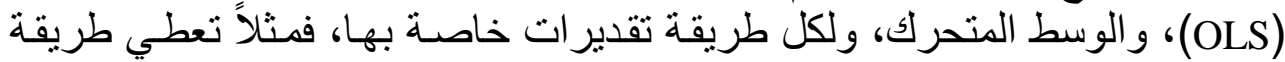

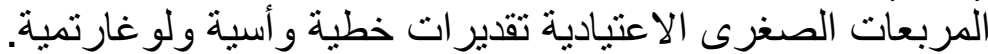

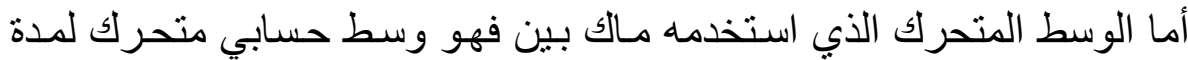

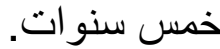
وفي ضوء المفهوم المذكور آنفاً يمكن تقدير متغير عدم الاستقرار بحسب

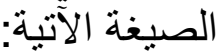

$$
E X I=\frac{X_{t}-X^{*}{ }_{t}}{X^{*}{ }^{*}}
$$

حيث إن EXI عدم استقرار عو ائد الصادرات الأولية.

القيم الفعلية للصادر ات الأولية في الددة t Xt

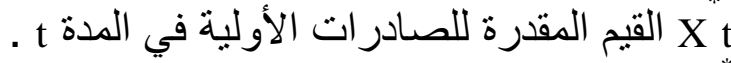

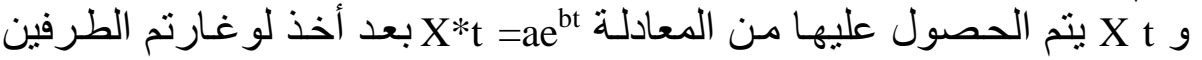
$\log X^{*} t=\log a+b t+e$ بعد إخضاع نتيجة هذه المعادلة إلى مقاييس الدقة.

ثانياً الصيخ المستخدمة في قياس نسب التبادل التجاري للصادرات الأولية

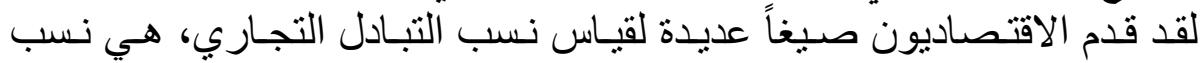

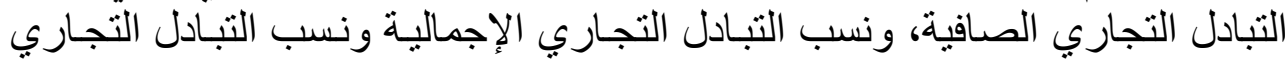

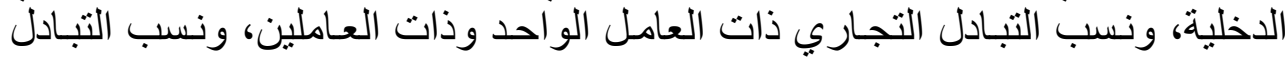

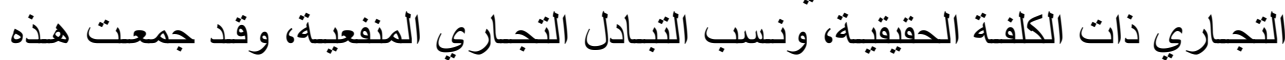

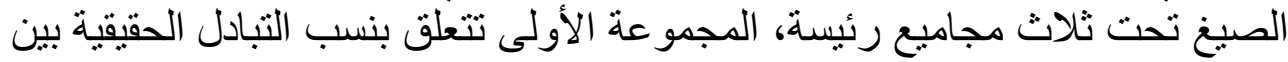

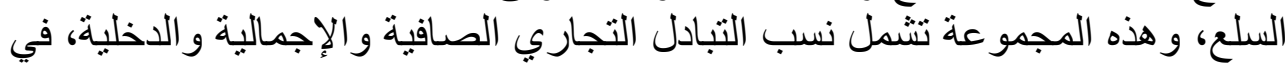

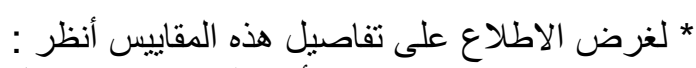

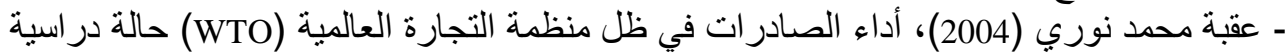

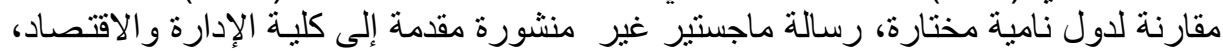




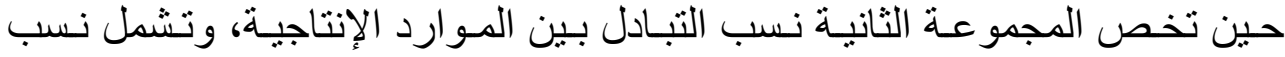

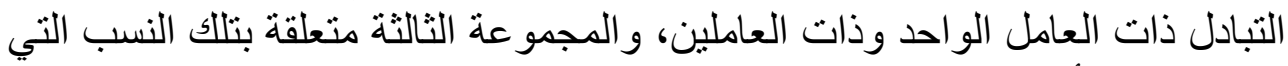

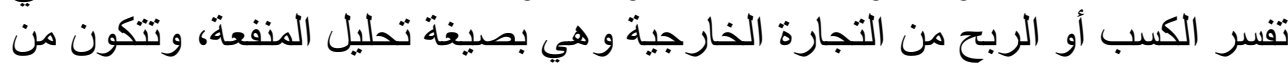

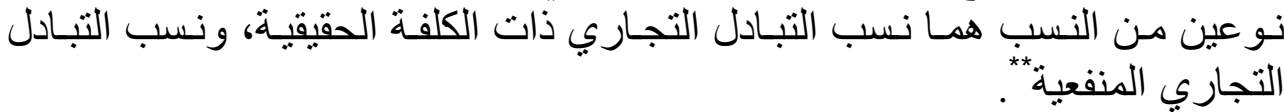

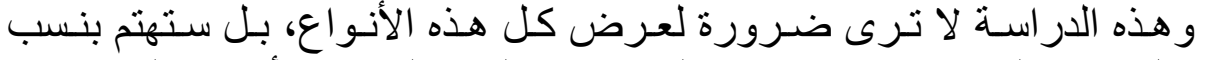

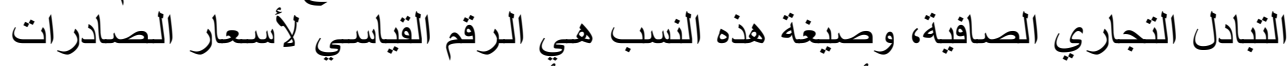

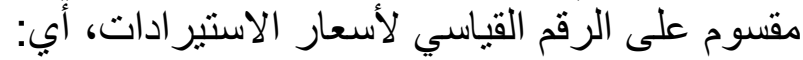

$$
\text { NBTT }=\frac{P_{x}}{P_{m}} \times 100
$$

$$
\begin{aligned}
& \text { حيث إن: } \\
& \text { NBTT } \\
& \text { P x } \\
& \text { الرقم القياسي لأسعار الاستير ادات. P m }
\end{aligned}
$$

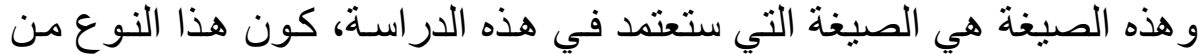

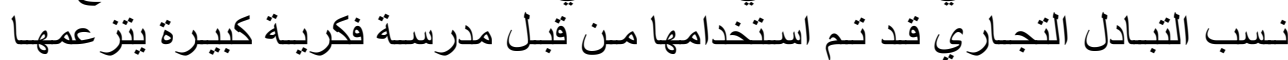

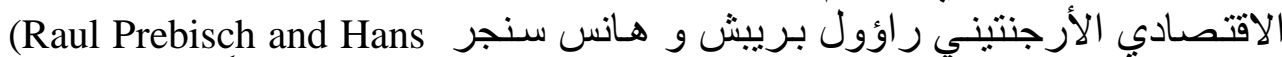

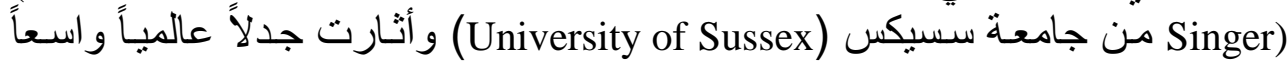

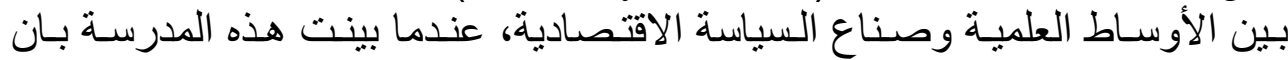

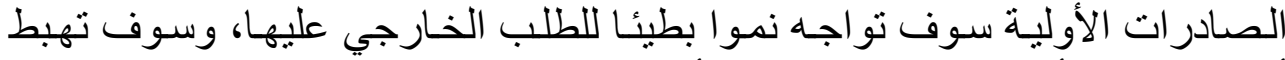

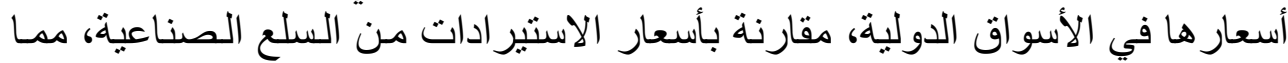

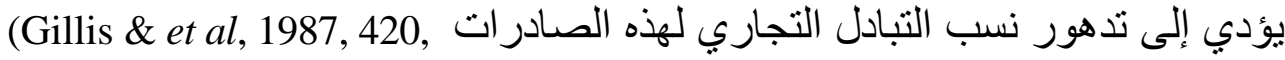

ثالثاً الصيغ المستخدمة في قياس تباطؤ الطلب الخارجي على الصادرات الأولية

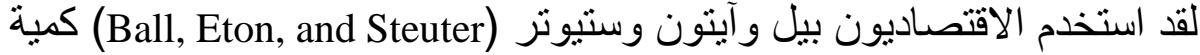

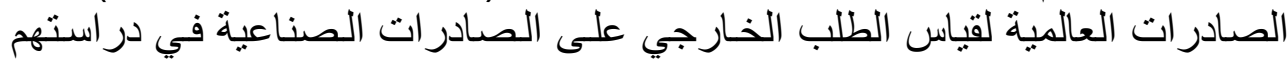
$\mathrm{F} \mathrm{d}=(\mathrm{Q} x)$ المنشورة عام 977 المادرات الصيغة المعتمدة هي:

$$
\mathrm{Fd}=(\mathrm{Q} x)
$$

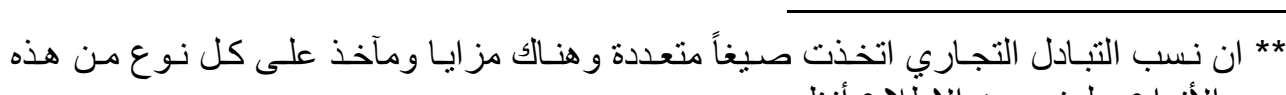

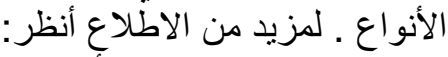

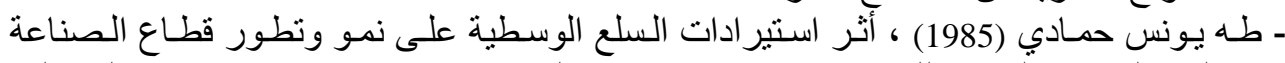

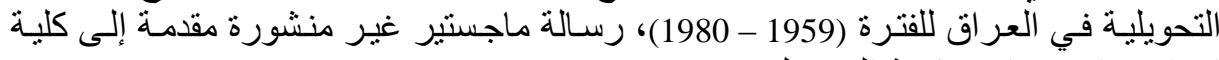




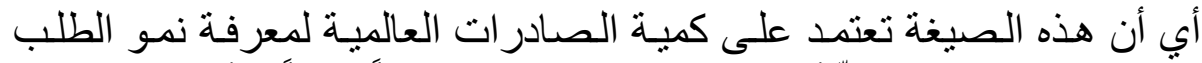

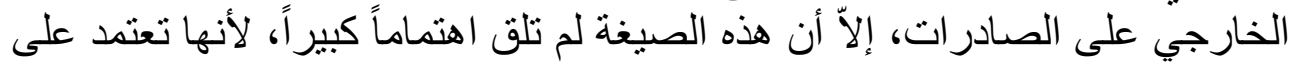

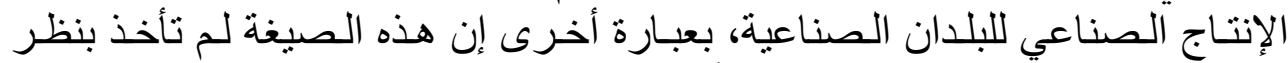

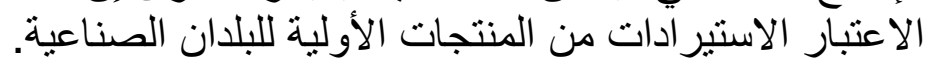

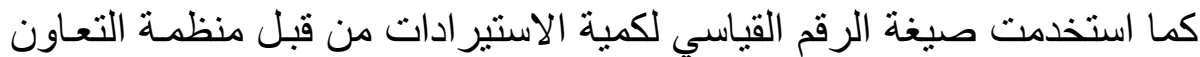

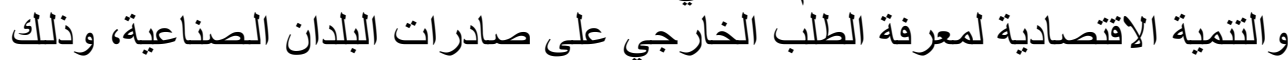

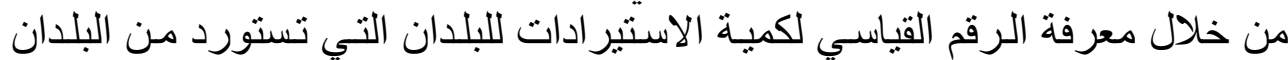

$$
\mathrm{Fd}=\mathrm{Q} \mathrm{m}
$$

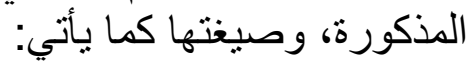
F الطلب الخارجي على الصادرات.

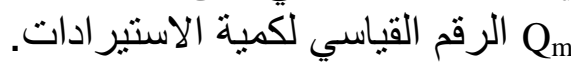

في حين استخدم سمايث (Smyth) معدل التغير التئرات السنوية في الصادرات مؤشراً

للطلب ألخارجي على صادر ات البلدان البنان الصناعية.

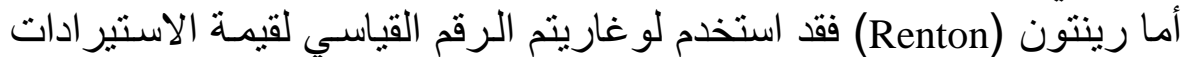

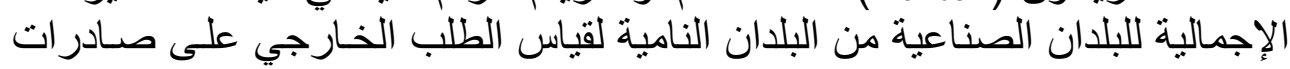

$$
\mathrm{F} \mathrm{d}=\mathrm{LOG}(\mathrm{VM})
$$
البلدان النامية، ويمكن كتابة هذه الصيغة بالئن التشكل الآتي:

الرقم القباسي لقيمة الاستير ادات للبلدان الصناعية من البلدان النامية.

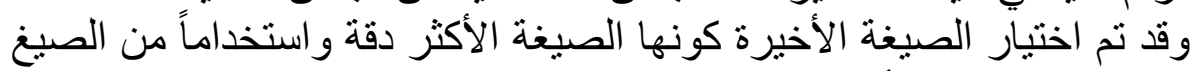

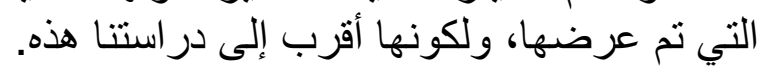

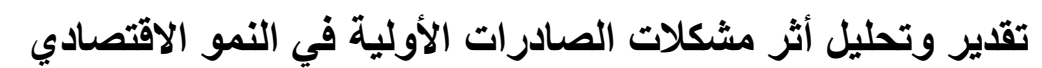

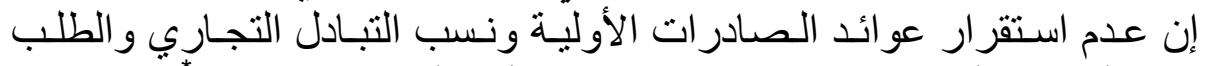

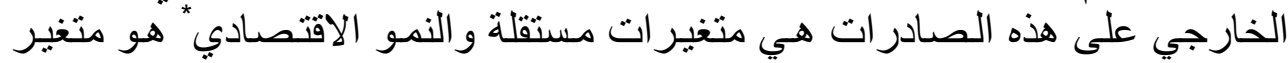

* إن معدل النمو الاقتصادي معبر عنه بمعدل نمو الناتج المحلي الاجمالي GDP بالأسعار الثابتة

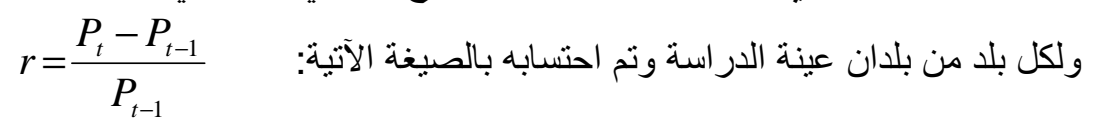

re معدل النمو، Pt-1 : مثئل الفترة الحالية والفترة السابقة (أو السنة الحالية والسنة السابقة)

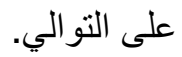

The World Bank, (2003). "World Development Indicators", P. 367. لمزيد من الاطلاّع انظر: 
تابع لكل بلد من بلدان عينة الدراسة، وقد استخدمنا صيغاً متعددة من نمـاذج القياس

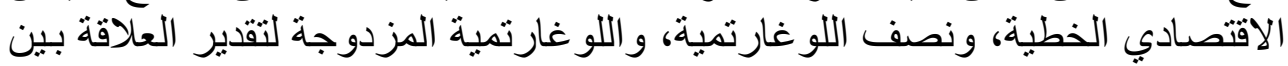

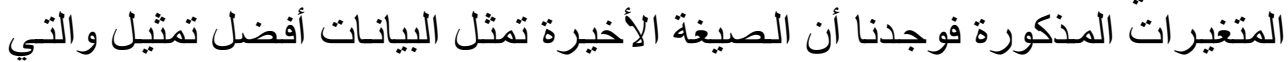
$\log _{\mathrm{Y}}=\mathrm{B}_{0}+\mathrm{B}_{1} \log \mathrm{EXI}+\mathrm{B}_{2} \log \mathrm{TOT}+\mathrm{B}_{3} \log \mathrm{FD}+\mathrm{U}$

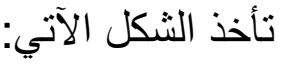

$$
\text { حيث إن : النمادي. : Y }
$$

EXI : عدم استقرار عو ائد الصادرات : : : الأولية. : نسب التبادل التجاري للصادر اتل التادرات الأولية. : TOT

الطلب الخارجي على ألصادرات الأولية التي تصدر ها بلدان عينة الدراسة. U

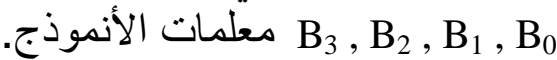

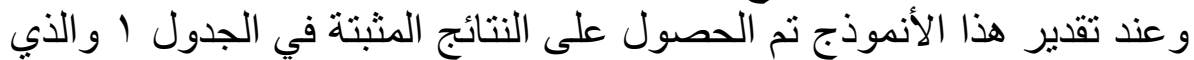

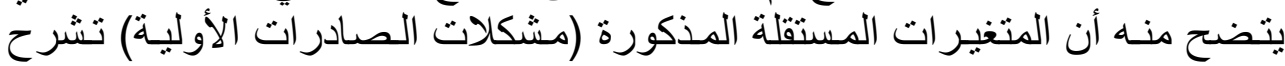

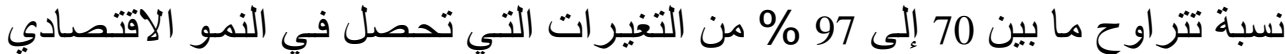

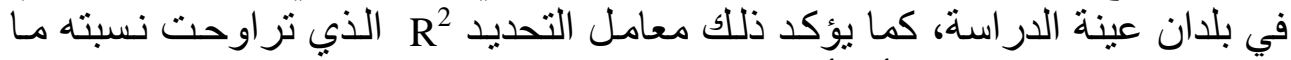

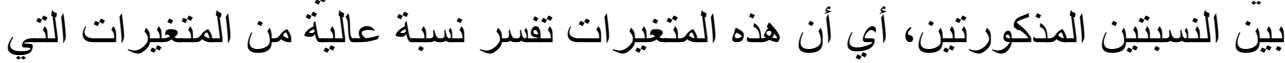

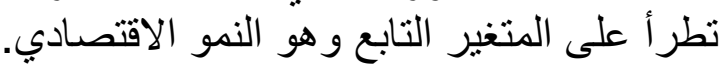

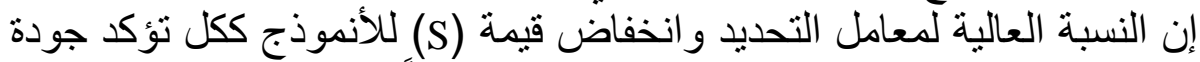

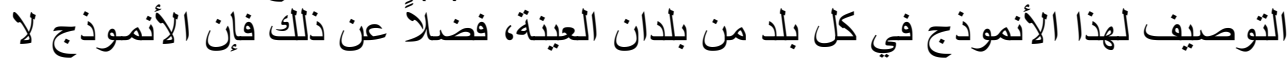

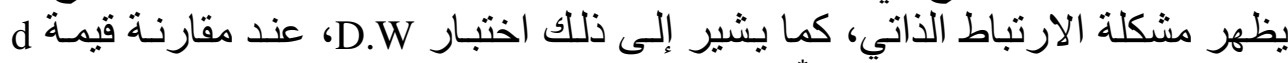
المحسوبة مع قيمتيها الجدوليتين. الارئ.

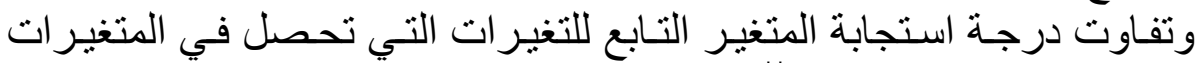

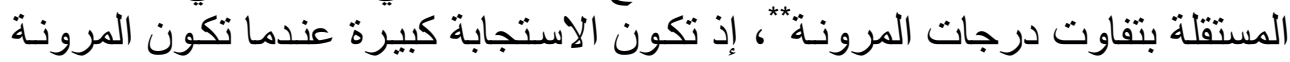
عالية وتقل هذه الاستجابة بانخفاضها.

* قيمـة d و d الجدولينتين للمشاهدات عددها (20) مشاهدة ولثلاثنة متغيرات مستقلة هما (1.70) و (0.79) على التو الي.

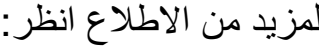

- Johnstone, J., (1972). "Econometric Method", 2nd Edtion, p. 430.

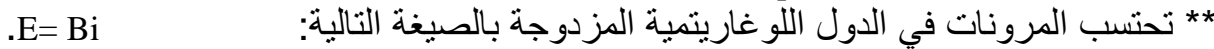

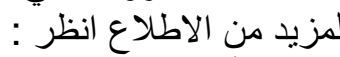

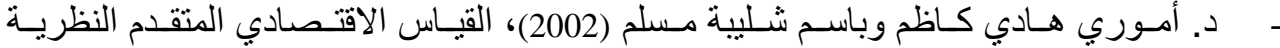

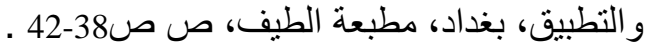

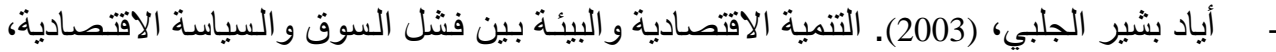

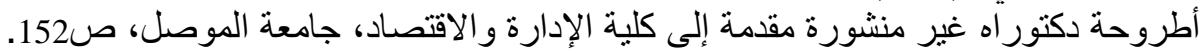




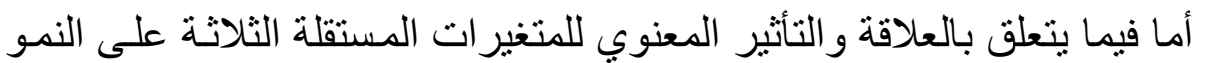

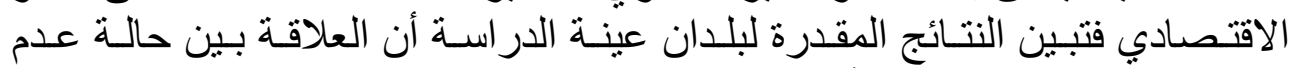

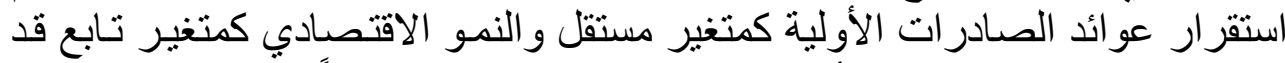

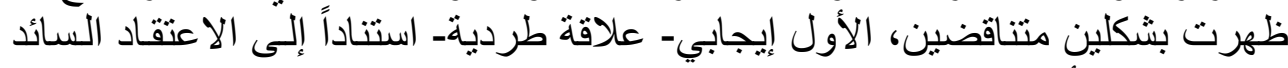

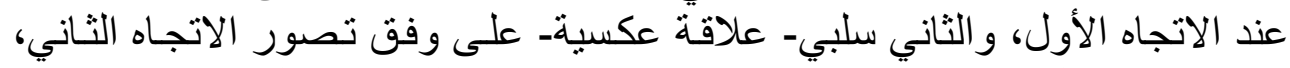

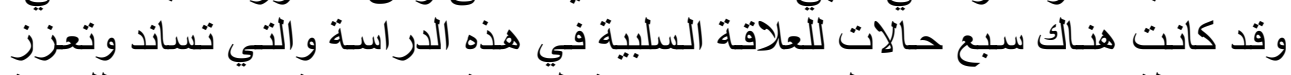

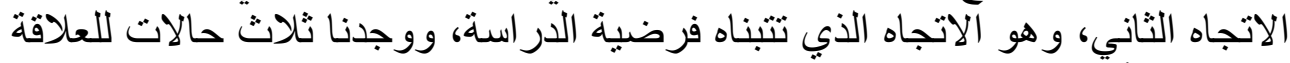

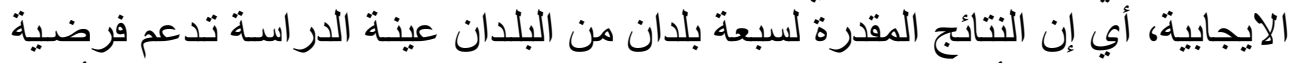

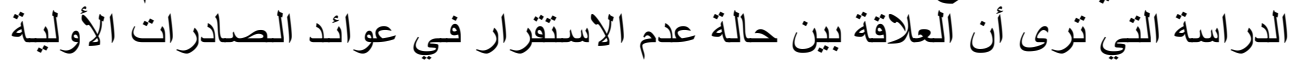

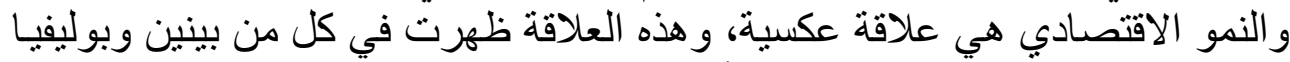

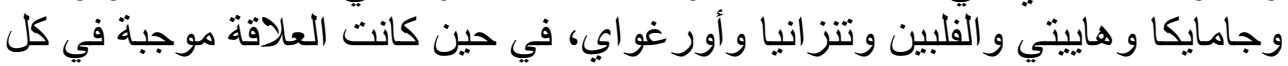

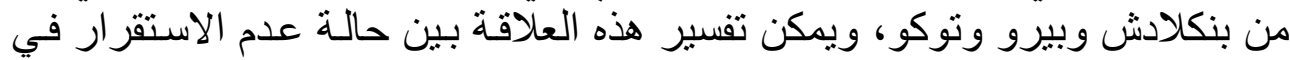

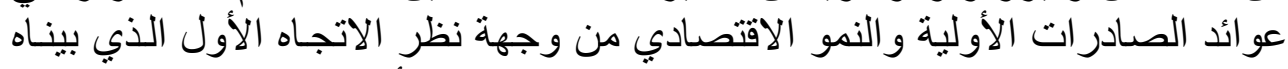

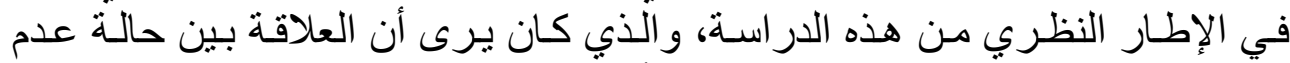

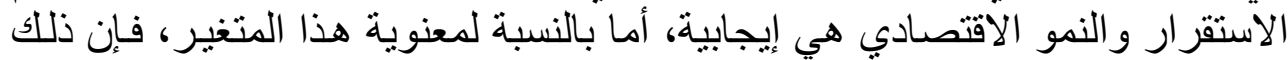

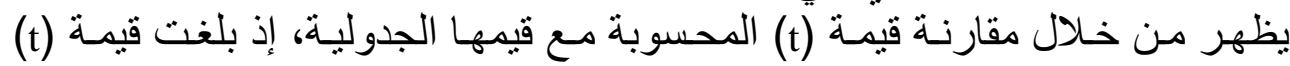

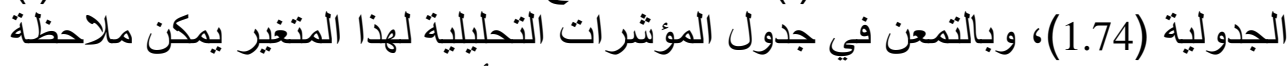

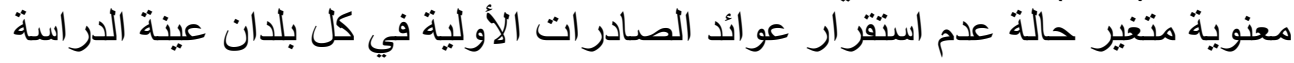

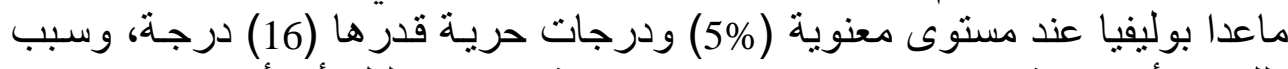

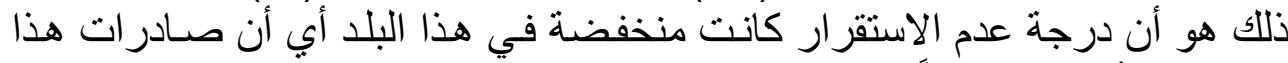

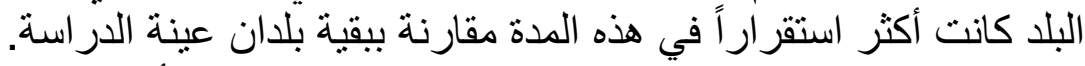

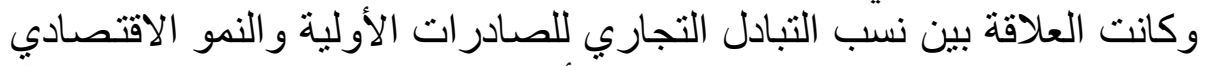

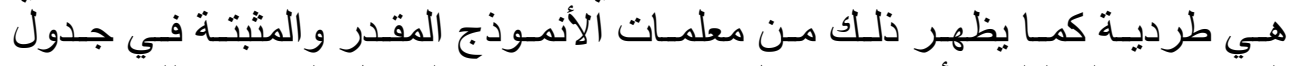

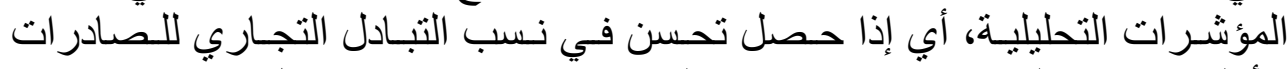

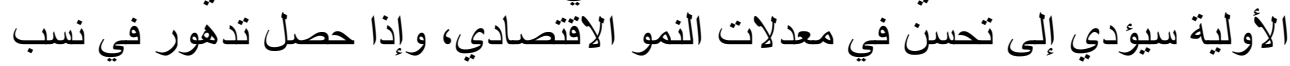

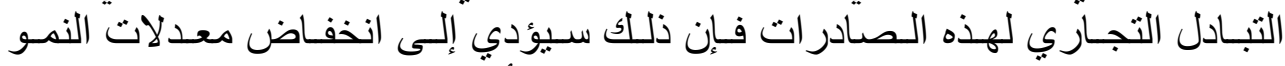

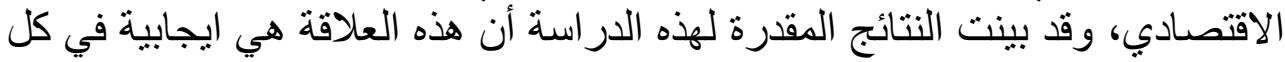

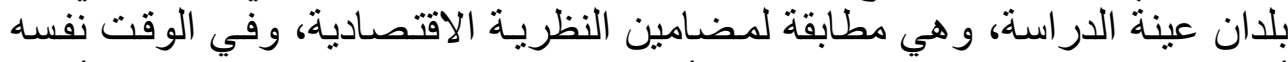

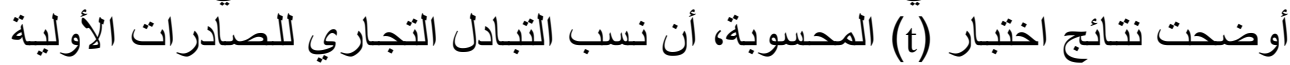

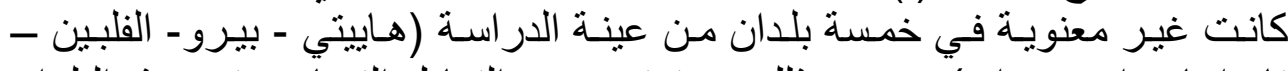

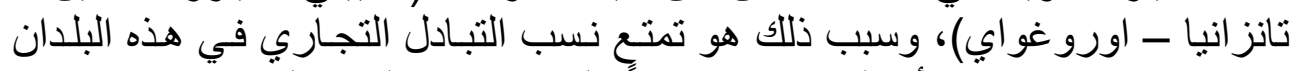

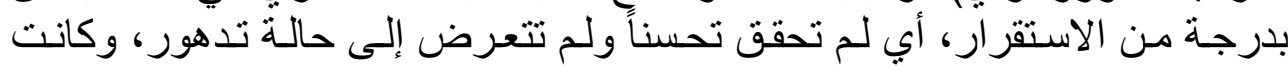

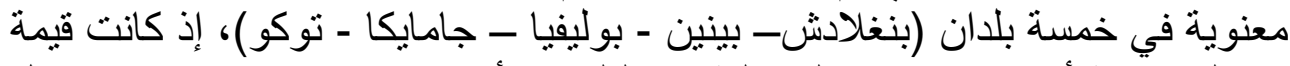

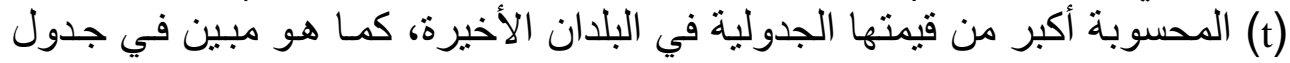
(المؤشر ات التحليلية). 


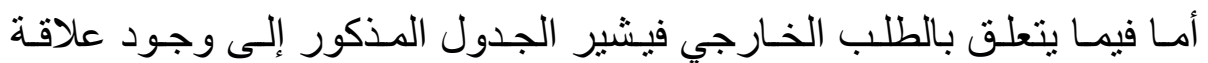

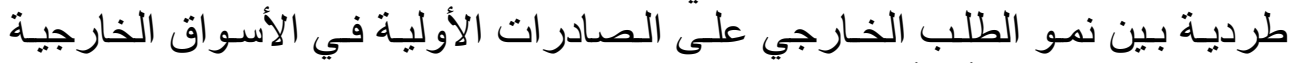

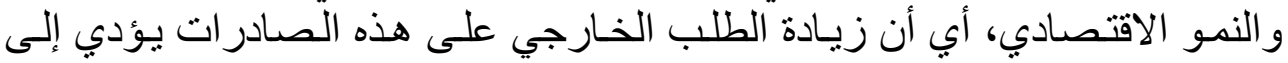

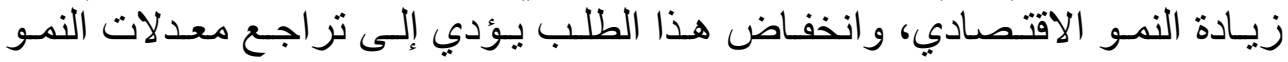

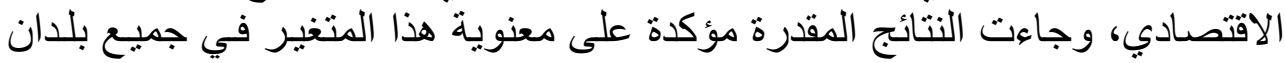

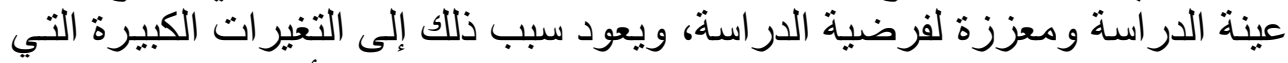

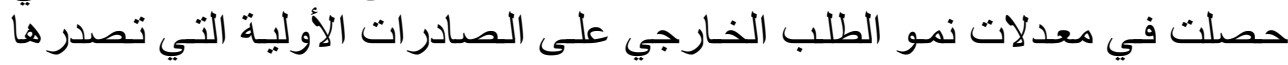
البلدان النامية.

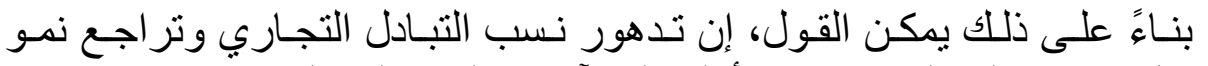

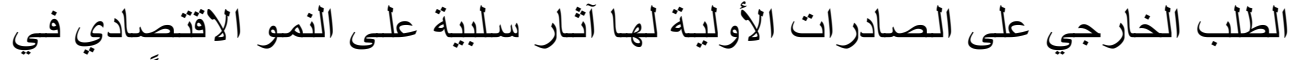

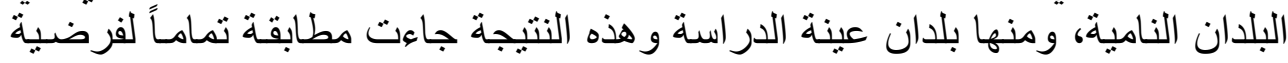

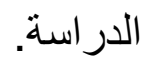

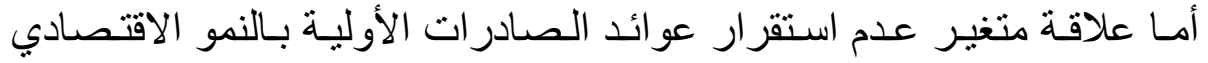

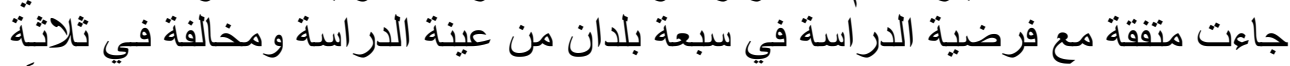

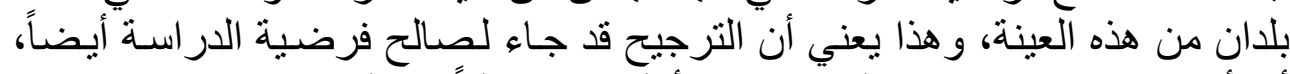

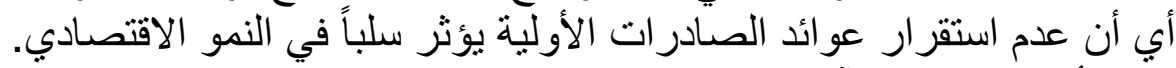

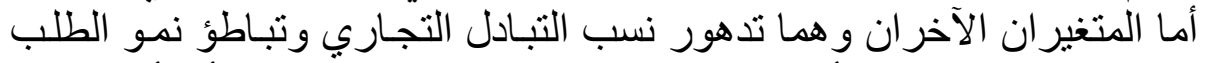

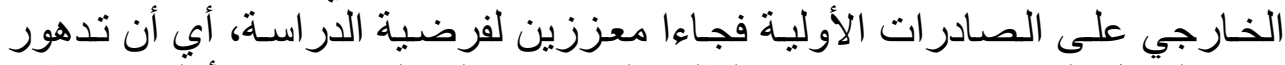

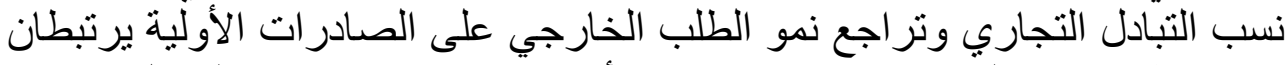

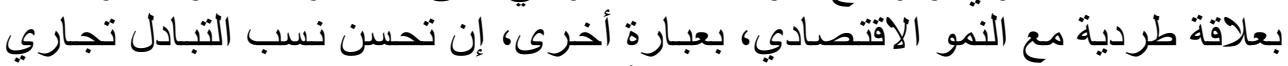

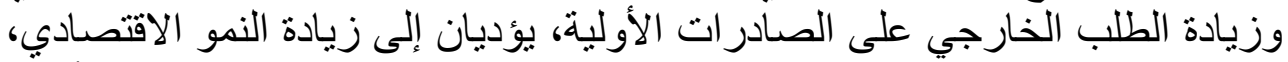

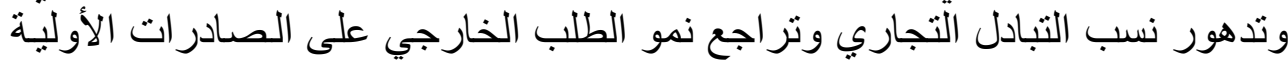
يتسبيان في تراجع معدلات النمو الاقتصادي.

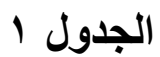

يبين المؤشرات التحليلية للأنموذج المقدر لبلدان عينة الدراسة

\begin{tabular}{|c|c|c|c|c|c|c|}
\hline المؤشرات البلان & $\mathbf{B}_{0}$ & $\mathbf{B}_{1}$ & $\mathbf{B}_{2}$ & $\mathbf{B}_{3}$ & $\mathbf{R}^{2}$ & DW \\
\hline بنغلادش & $\begin{array}{l}-59.956 \\
(19.50) \\
0.056\end{array}$ & $\begin{array}{l}0.057 \\
(4.07) \\
0.014\end{array}$ & $\begin{array}{l}0.252 \\
(1.80) \\
0.141\end{array}$ & $\begin{array}{l}18.691 \\
(2.45) \\
0.914\end{array}$ & 97 & 1.89 \\
\hline n & $\begin{array}{l}-13.747 \\
(7.87) \\
1.746 \\
0.017\end{array}$ & $\begin{array}{l}-0.037 \\
(6.53) \\
0.005\end{array}$ & $\begin{array}{l}0.161 \\
(3.66) \\
0.044\end{array}$ & $\begin{array}{l}4.315 \\
(8.24) \\
0.523\end{array}$ & 97 & 2.13 \\
\hline Bolivia بوليفيا & $\begin{array}{l}-7.397 \\
(7.99) \\
0.926 \\
0.015\end{array}$ & $\begin{array}{l}-0.006 \\
(1.58) \\
0.003\end{array}$ & $\begin{array}{l}0.079 \\
(2.06) \\
0.038\end{array}$ & $\begin{array}{l}2.726 \\
(9.87) \\
0.276\end{array}$ & 90 & 1.86 \\
\hline
\end{tabular}




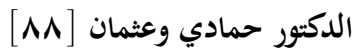

\begin{tabular}{|c|c|c|c|c|c|c|}
\hline المؤشرات البلدان & $\mathbf{B}_{0}$ & $\mathbf{B}_{1}$ & $\mathbf{B}_{2}$ & $\mathbf{B}_{3}$ & $\mathbf{R}^{2}$ & DW \\
\hline Jamaica & $\begin{array}{l}-30.288 \\
(7.02) \\
4.317 \\
0.044\end{array}$ & $\begin{array}{l}-0.873 \\
(6.23) \\
0.014\end{array}$ & $\begin{array}{l}0.436 \\
(4.00) \\
0.109\end{array}$ & $\begin{array}{l}9.647 \\
(7.45) \\
1.294\end{array}$ & 97 & 1.98 \\
\hline هاييتي & $\begin{array}{l}-19.565 \\
(6.43) \\
3.041 \\
0.053\end{array}$ & $\begin{array}{l}-0.099 \\
(3.39) \\
0.029\end{array}$ & $\begin{array}{l}0.145 \\
(0.97) \\
0.149\end{array}$ & $\begin{array}{l}6.368 \\
(6.86) \\
0.927\end{array}$ & 84 & 1.87 \\
\hline بيرو & $\begin{array}{l}-59.69 \\
(5.58) \\
10.59 \\
0.185 \\
\end{array}$ & $\begin{array}{l}0.027 \\
(6.63) \\
0.043\end{array}$ & $\begin{array}{l}0.308 \\
(0.45) \\
0.688\end{array}$ & $\begin{array}{l}18.333 \\
(5.73) \\
3.202\end{array}$ & 70 & 2.12 \\
\hline Philippens الفلبين & $\begin{array}{l}-11.486 \\
(12.41) \\
0.925 \\
0.016\end{array}$ & $\begin{array}{l}-0.074 \\
(4.00) \\
0.018\end{array}$ & $\begin{array}{l}0.006 \\
(0.38) \\
0.016\end{array}$ & $\begin{array}{l}3.747 \\
(13.53) \\
0.276\end{array}$ & 94 & 1.93 \\
\hline Tanzania & $\begin{array}{l}-57.507 \\
(5.82) \\
9.873 \\
0.150\end{array}$ & $\begin{array}{l}-0.343 \\
(3.29) \\
0.104\end{array}$ & $\begin{array}{l}0.063 \\
(0.32) \\
0.198\end{array}$ & $\begin{array}{l}18.146 \\
(6.18) \\
2.937\end{array}$ & 88 & 1.99 \\
\hline Togo & $\begin{array}{l}-12.060 \\
(7.79) \\
1.547 \\
0.030\end{array}$ & $\begin{array}{l}0.019 \\
(2.97) \\
0.006\end{array}$ & $\begin{array}{l}0.038 \\
(1.90) \\
0.035\end{array}$ & $\begin{array}{l}3.785 \\
(8.20) \\
0.461\end{array}$ & 82 & 2.27 \\
\hline اورغواي & $\begin{array}{l}-3.576 \\
(10.4) \\
0.344 \\
0.006\end{array}$ & $\begin{array}{l}-0.006 \\
(4.41) \\
0.001\end{array}$ & $\begin{array}{l}0.037 \\
(1.33) \\
0.027\end{array}$ & $\begin{array}{l}.644 \\
(16.0) \\
0.102\end{array}$ & 95 & 1.79 \\
\hline
\end{tabular}

- الصف الأول يمثل معلمات الأنموذج المقدر (B)

ـ الصف الثاني القيم بين الأقواس تمثل (t) المحتسبة علماً بأن قيمتها الجدولية عند مستوى معنوية 5 \% ـ ودرجات حرية قدرها 16 درجة هي (1.74).

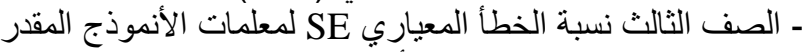
- الصف الرابع يمثل قيمة (S) للأنموذج ككل.

الاستتتاجات والمقترحات

لقد توصلت الدراسة إلى الاستنتاجات و التوصيات الآتية: أولاً - الاستثتاجات

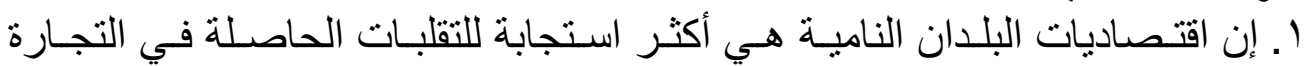

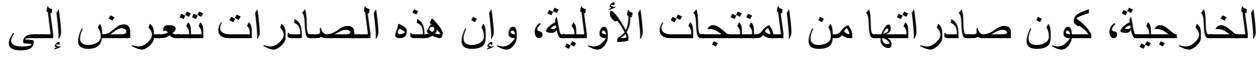

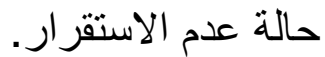
r. استتنجت الدر اسة أنه للوصول الإنى اللى تحقيق مستويات ملحوظة من النمو الاقتصـادي

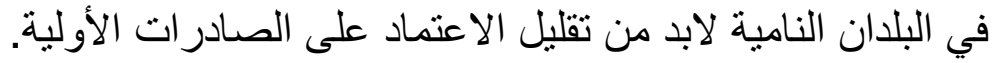


r. إن نمو الطلب الخارجي على الصادرات الأولية للبلدان الناميـة يواجـه تباطؤاً حـاداً

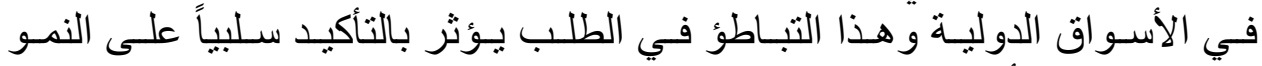

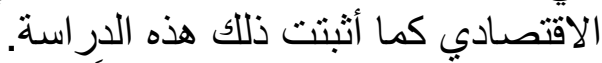

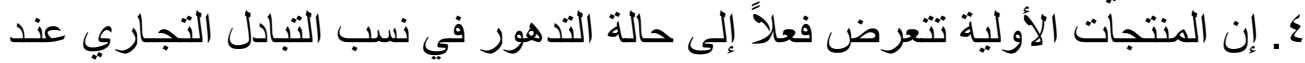

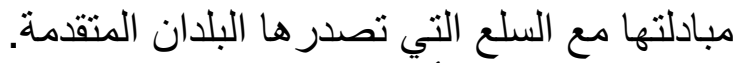

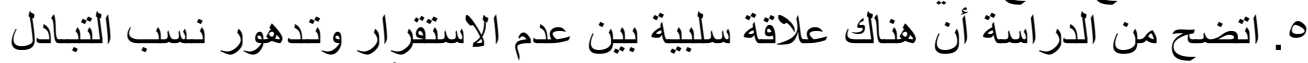

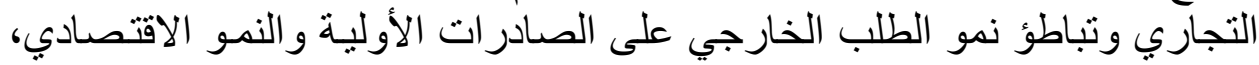
و هذا ما تم إثباته في نتائج التقدير القياسي لعينة الدراسة.

\section{ثانياً - التوصيات}

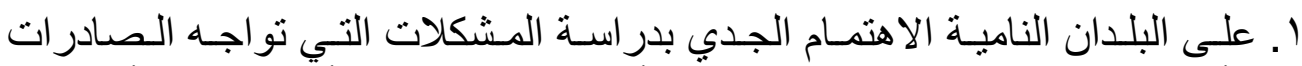

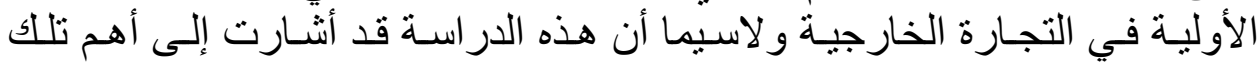

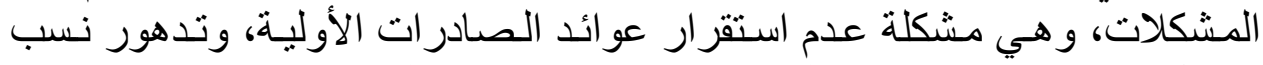

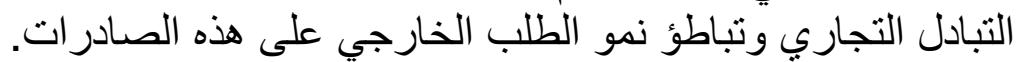

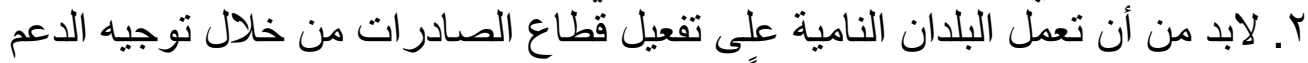

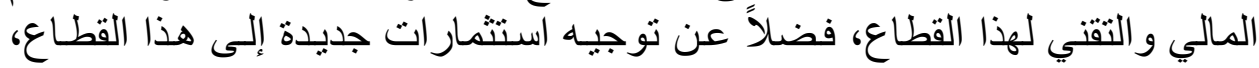

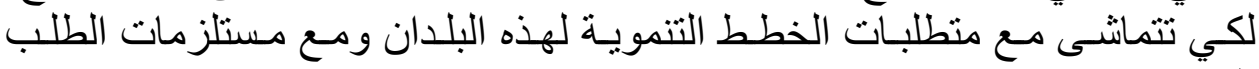

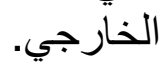

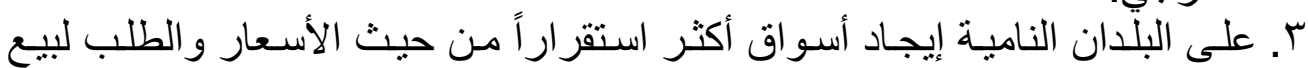

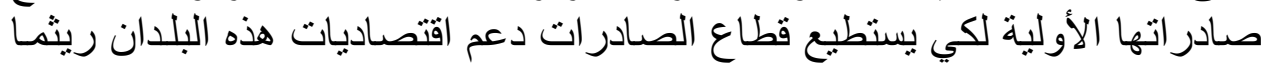

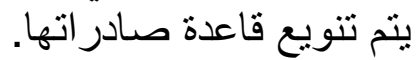

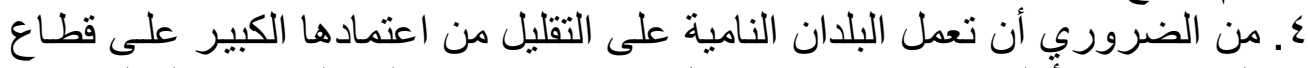

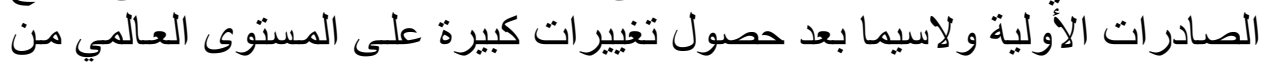

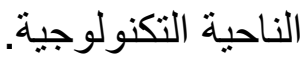
ه. نوصي الدراسة ببحث مشكلة أخرى من المشكلات التي تواجه الصادرات الأولية،

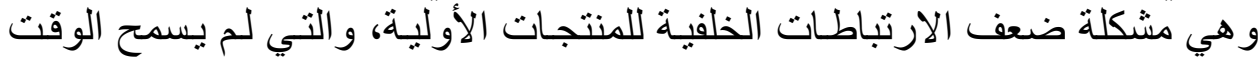
بدر استها مع المشكلات قيد الدر اسة.

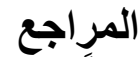

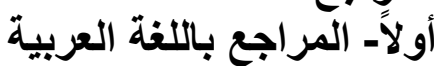

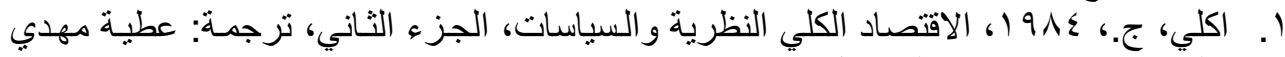

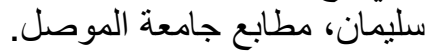

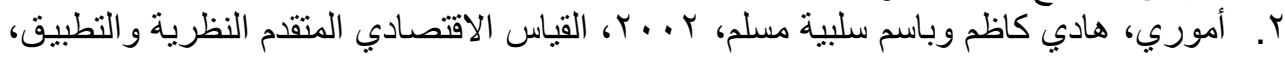

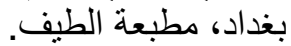

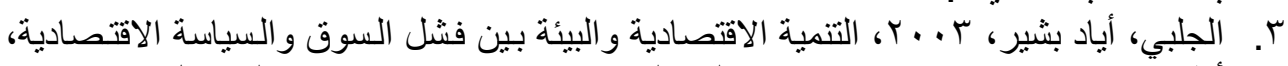

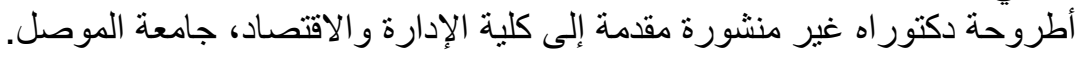




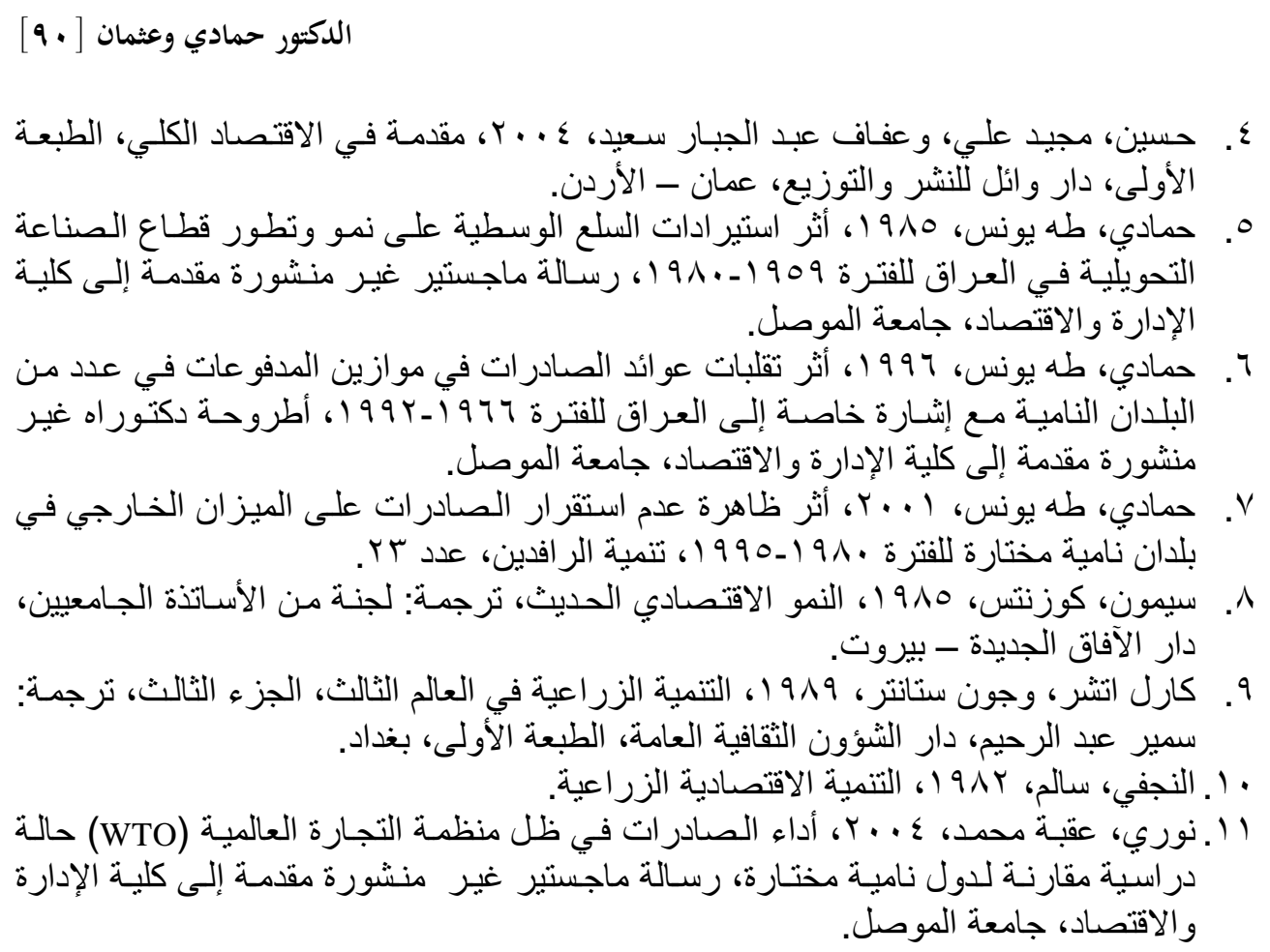

\section{ثانياً المراجع باللغة الأجنبية}

1.Anderson, K., 2004, "Agriculture, Trade Reform and Poverty Reduction: Implications from Sub-Saharan Africa", Centre for International Economic Studies, Australia.

2. Blattman, C., Hwang, J. G. Williamson, 2004, "The Impact of the Terms of Trade on Economic Development in The Periphery; 1870-1939: Volatility and Secular Change" National Bureau of Economic Research, Working Paper No.: 10600.

3. Cremer, G. L. \& Jensen, D. D. Southgate, 1997, Agricultural Economics and Agribusiness", Seventh Edition.

4. Daniel, P. W. and W. F. Lever, 1998, "The Global Economy in Transition", LONGMAN.

5.Dean, J. M., 1990, "The Effects of The U.S. MFA on Small Exports", The Review of Economics and Statistics, Vol. LXXLL, No.: 1.

6. Dipendra Sinla, 1999, "Export Instability Investment and Economic Growth in Asian Countries: A Time Series Analysis", Economic Growth Center, Yale University, Australia.

7.Dunn, R. M. \& Ingram, J. C., 1999, International Economics", Fourth Edition, New York.

8. Esser, K., 1990, "Latin America in Crisis-Neo-Structuralism As an Economic Policy Response", Economics, Vol. 41.

9. Fischer, B., 1981, "Interest Rate Ceilings Inflation and Economic Growth in Development Countries", Economics, Vol. 23.

10. Gillis, M., et al., 1987, "Economics of Development", $2^{\text {nd }}$ ed. Norton, NEW.

11. Gottschalk, R. \& Prates, 2006, "East Asia's Growing Demand for Primary CommoditiesMacroeconomic Challenges for Latin America", New York.

12. Hyman, D. N., 1994, "Macroeconomics", Third Edition.

13. Johnstone, J., 1972. "Econometric Method", 2nd Edtion.

14. Lim, D., 1980, "Distribution, Export Instability and Saving Behavior", Economic Development and Cultural Changes, Vol. 28, No.: 2. 
15. Lipesey, R. E., 1994, "Quality Change and Other Influences on Measures of Export Prices of Manufactured Goods and The Terms of Trade Between Primary Products and Manufactures", National Bureau of Economic Research, Working Paper No.: 4671.

16. Love, J., 1985, "Export Instability: An Alternative Analysis of Causes", The Journal of Development Studies, Vol. 21.

17. MacBean, A., 1964, "Causes of Excessive Flactuations in Export Proceeds of Underdeveloped Countries".

18. MacBean, A., 1964, "Causes of Excessive Flactuations in Export Proceeds of Underdeveloped Countries".

19. Paulo, S., 2004, "Economic Development and Capital Accumulation: Recent Experience and Policy Implications", Eleventh Session, Division on Globalization and Development Strategies.

20. Salvatore, D., 2004, "International Economics", Fordham University, Eighth Edition, John Wiley \& Sons., INC.

21. Singh, B., Drost, H. and Kumar, R. C., 1988, "An Empirical Evaluation of the Relative, the Permanent Income and the Life - Cycle Hypothesis", Economic Development and Cultural Changes, Vol. 5, No.: 1981.

22. The World Bank, 2003. "World Development Indicators".

23. Todaro, M. P., 2000, "Economic Development", Seventh Edition, New York University.

24. UNCTAD 2003, "Economic Development in Africa, Trade Performance and Commodity Dependence", New York.

25. UNCTAD 2003, "World Statistics Pocket Book Least Developed Countries", New York, internet: http://www.un, org/pubs.

26. UNCTAD, 2005 , "The Standard International Trade Classification Revision 3" , 2005.

27. UNCTAD, 2005, "Globalization of R \& D and Developing Countries", New York and Geneva.

28. UNCTAD, 2005, "Information Economy Report 2005", New York and Geneva.

29. UNCTAD, 2005, "World Investment Report", New York and Geneva, New York: www. Unctad.org.

30. UNCTAD, 2006, "East Asia's Growing Demand for Primary CommoditiesMacroeconomic Challenges for Latin America", New York.

31. UNCTAD, 2006, "Trade and Development Report", New York and Geneva.

32. UNCTAD, 2006, "Trade and Environment Review 2006", New York and Geneva.

33. UNCTAD, 2006, "World Economic Situation and Prospects", New York.

34. United Nations, 2005, "World Economic and Social Survey 2005 Financing for Development", department of Economic and social Affairs New York, 2005.

35. United Nations, 2005, "World Economic and Social Survey 2005 Financing for Development", department of Economic and social Affairs New York, 2005.

36. Vaish, MC., 1977. "Money ; Banking and International and Trade", 4th Ed.

37. WTO, 2004, "Economic and SocialImpacts of Trade Liberalization", by: Tussie, D. \& Aggio, C. 